\title{
PLA-b-PEG/magnetite hyperthermic agent prepared by Ugi four component condensation
}

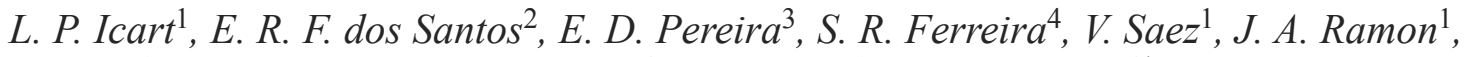 \\ M. Nele ${ }^{2}$, J. C. S. Pinto ${ }^{5}$, R. D. Toledo ${ }^{4}$, D. Z. Silva ${ }^{1}$, F. G. Souza Jr ${ }^{4 *}$ \\ ${ }^{1}$ Departamento de Macromoléculas, Centro de Biomateriales, Universidad de la Habana, av. Ronda 4400, Vedado, \\ La Habana, Cuba \\ ${ }^{2}$ Escola de Química, Centro de Tecnologia-Cidade Universitária, av. Horacio Macedo, bloco E. Universidade Federal de \\ Rio de Janeiro, 2030 Rio de Janeiro, Brasil \\ ${ }^{3}$ Instituto de Macromoléculas: Professora Eloisa Mano, Centro de Tecnologia-Cidade Universitária, av. Horacio Macedo, \\ 2030, bloco J. Universidade Federal de Rio de Janeiro, 2030 Rio de Janeiro, Brasil \\ ${ }^{4}$ Programa de Engenharia Civil, COPPE, Centro de Tecnologia-Cidade Universitária, av. Horacio Macedo, bloco I. \\ Universidade Federal de Rio de Janeiro, 2030 Rio de Janeiro, Brasil \\ ${ }^{5}$ Programa de Engenharia Química, COPPE, Centro de Tecnologia-Cidade Universitária, av. Horacio Macedo, bloco G. \\ Universidade Federal de Rio de Janeiro, 2030 Rio de Janeiro, Brasil
}

Received 6 July 2015; accepted in revised form 1 October 2015

\begin{abstract}
Ugi four component condensation (UFCC), is an important tool for the synthesis of different types of bioconjugate species. In this study, a PLA-PEG/magnetite magnetic composite was prepared by a synthetic-route approach based on UFCC. In particular, poly(lactic acid) (PLA) was synthesized by autocatalytic polycondensation. Also, poly(ethyleneglycol) bis-amine (bis-amine PEG) was synthesized by two different methods: via carbonyldiimidazol (CDI)/ethylenediamine (ED) $(75 \%$ yield) and via chlorate monochlorated acetyl (CCA)/ED (95\% yield). All products were characterized by gel permeation chromatography (GPC), hydrogen-1 nuclear magnetic resonance (NMR ${ }^{1} \mathrm{H}$ ), Fourier transform infrared (FTIR), differential scanning calorimetry (DSC) and thermogravimetric analysis (TGA). In addition, magnetite was prepared and modified to generate aldehyde groups which are also necessary for UFCC. This product was characterized by DSC, TGA, X-ray diffraction (XRD) and magnetic force (MF) techniques. Also, the magnetic composite PLA-PEG/magnetite was synthesized by UFCC. The calculated yield was equal to $80 \%$. Furthermore, magnetic microspheres were prepared by the procedure of emulsion solvent-evaporation and characterized by scanning electron microscopy (SEM) and magnetic induction hyperthermia (MIH). The main contribution of these results is to propose a new application for UFCC in the preparation of biomasked magnetic drug delivery systems able to improve the cancer treatment and even the welfare of the patients.
\end{abstract}

Keywords: biodegradable polymers, Ugi reaction, magnetic composites, hyperthermic agent

\section{Introduction}

Drug delivery systems (DDS) is one of the most exciting research fields of pharmacy, chemistry and other related sciences [1-8]. The clinical benefits have been demonstrated by dozens of products that have already been approved for use in humans and several types of DDS have been approved by regulatory agencies [9].

Many of these systems are based on polymers. Among them, the most widely used are polyethylene glycol (PEG) and the poly(lactic acid) family, including its copolymers with glycolic acid $[9,10]$. The

\footnotetext{
${ }^{*}$ Corresponding author, e-mail: fgsj@ufrj.br

(C) BME-PT
} 
most important feature of PEG is its potential for biomasking [11-13]. The conjugation of PEG to DDS or drugs (e.g. peptides and proteins) prevents recognition by the various defense systems of organisms [14-16].

In turn, PLA or poly(lactic/glycolic acid) (PLGA) copolymers have been widely studied with regard to the controlled release of drugs occluded in this matrix by diffusion or erosion of biodegradable polymers [17-21]. Since 1987, there have been 1042 reports of DDS, based on PEG-PLA or the PLGA polymeric system. However, in the last five years, 600 papers were published, which suggests a remarkable level of interest in this scientific field. The properties and applications of DDS can be improved by the use of magnetic particles. These composites have the potential to be targeted to a specific site by using magnetic fields. In addition, they could be very useful in magnetic hyperthermia therapy [22-25].

Magnetic particles modified with biodegradable PLGA or PLA were firstly prepared in the beginning of the 1990s by chemical adsorption or molecular interactions between a reactive polymer end group and the surface of the particle [26-30]. On the other hand, the surface modification of magnetic particles by chemical linkage of polymers is less documented, even less by the use of Ugi four component condensation (UFCC).

The main objective of this study was to prepare a new system of controlled drug release, based on the union of the three elements mentioned above (i.e. PLA, PEG and magnetic particles) and using Ugi four component condensation (UFCC) [31]. This reaction is useful to the functionalization and PEGylation of biomacromolecules based on glycoprotein [32], lipoprotein [33] and polymeric conjugates [34-36]. UFCC is a condensation reaction in which an aldehyde or a ketone, an amine, an isocyanide, and a carboxylic acid can form a bis-amide. It is considered a prime example of a multi-component reaction (MCRs) which proceeds by the formation of an imine as a result of condensation of the aldehyde and primary amine. Afterwards, the isocyanide and carboxylic acid are added to the imine intermediate which, via an acyl transfer, rearranges to the bis-amide product [37].

This new DDS could be used in very interesting applications, such as (i) the occlusion of hydrophobic drugs in the PLA phase, which can be released by diffusion and erosion of the polymer matrix; (ii) the con- jugation of targeting elements to the amino end groups of the PEG chain; (iii) the production of biomasking by PEG chains, increasing the lifetime of the system; (iv) additional targeting capability due to the presence of the magnetic iron oxide core; and (v) use of the phenomenon of magnetic hyperthermia. Therefore, the presented material is very interesting due to the advantages of Ugi reaction, which make the synthetic route less expensive and enables easier manipulation of the reagents used. In addition, it can increase the efficiency of treatments, improving the welfare of patients.

\section{Experimental \\ 2.1. Materials}

Lactic acid (85\%), $\mathrm{FeCl}_{3} \cdot 6 \mathrm{H}_{2} \mathrm{O}, \mathrm{FeSO}_{4} \cdot 7 \mathrm{H}_{2} \mathrm{O}, \mathrm{KOH}$, glutaraldehyde (50\%), reduced $\mathrm{Fe}, \mathrm{CoSO}_{4} \cdot 7 \mathrm{H}_{2} \mathrm{O}$ and $\mathrm{CuSO}_{4} \cdot 5 \mathrm{H}_{2} \mathrm{O}$, polyvinyl alcohol (PVA) and ethylenediamine were purchased from VETEC. PEG $\left(M_{\mathrm{n}}\right.$ 6000), carbinyldiimidazole (CDI), chlorate monochlorated acetyl (CCA) and tert-butyl isocyanide were purchased from SIGMA-ALDRICH.

\subsection{Synthesis of PLA polymeric system by autocatalytic polycondensation}

The PLA polymer was synthesized from $85 \%$ lactic acid $(700 \mathrm{~mL})$, in a closed system with slight vacuum $(-550 \mathrm{~mL} / \mathrm{mm} \mathrm{Hg})$. The reaction medium was kept at $180^{\circ} \mathrm{C}$ for $12 \mathrm{~h}$. The product of the reaction was purified by solubilization in chloroform $(250 \mathrm{~mL})$ and precipitation in cold ethanol $(4 \mathrm{~L})$.

\subsection{Synthesis of end amine functionalized PEG 2.3.1. Via CDI/ED}

PEG $(0.5 \mathrm{~g})$ dissolved in dichloromethane $(70 \mathrm{~mL})$ was reacted with an appropriate amount of CDI (10 equivalent) overnight, at room temperature under stirring. Soon afterwards, the reaction mixture was concentrated by rotoevaporation and the activated PEG was purified by three precipitations in cold diethyl ether $(140 \mathrm{~mL})$ and filtered under a slight vacuum. The purified activated PEG (0.1 g) dissolved in dichloromethane $(14 \mathrm{~mL})$ was reacted with appropriate amounts of ethylenediamine (10 equivalent) overnight, at room temperature under stirring. Then, the reaction mixture was concentrated by rotoevaporation and diafiltered against distilled water, (cellulose acetate membrane, $1 \mathrm{kDa}$ cutoff). Finally, the bis-amine PEG was dried by lyophilization. 


\subsubsection{Via CCA/ED}

PEG (5 g) dissolved in $100 \mathrm{~mL}$ hexane/dichloromethane $(1.1 \mathrm{vv})$ was reacted with an appropriate amount off CCA ( 6 equivalent) for 8 hours, at room temperature and under stirring. Then, the reaction mixture was kept under nitrogen atmosphere for 30 minutes. Immediately following this, $14 \mathrm{~mL}$ of ethanol was added and the system was kept under reflux for 30 minutes. Finally, the reaction mixture was concentrated by rotoevaporation until $50 \mathrm{~mL}$. Suddenly the activated PEG was reacted with appropriate amounts of ethylenediamine (10 equivalents) for 48 hours at room temperature and stirring. The final product was purified by precipitation in diethyl ether $(250 \mathrm{~mL})$ followed by slight vacuum filtration.

\subsection{Synthesis of magnetite and aldehyde-modified magnetite}

Magnetite was prepared as described in the literature [38]. Briefly, in separate vessels, $3.375 \mathrm{~g}$ (2.5 mmol) of $\mathrm{FeCl}_{3} \cdot 6 \mathrm{H}_{2} \mathrm{O}$ and $3.475 \mathrm{~g}(2.5 \mathrm{mmol})$ of $\mathrm{FeSO}_{4} \cdot 7 \mathrm{H}_{2} \mathrm{O}$ were dissolved in $100 \mathrm{~mL}$ of deionized water. Subsequently, these two solutions were mixed and then $50 \mathrm{~mL}$ of aqueous solutions of $\mathrm{KOH}$ $2 \mathrm{M}$ were added rapidly under stirring; the final product was a black precipitate that is attracted by a neodymium magnet. The magnetite was washed three times with deionized water and once with ethanol using magnetic decantation. The final product was dried at room temperature. The purified magnetite mixed in distilled water $(75 \mathrm{~mL})$ was reacted, first with glutaraldehyde $50 \%(10 \mathrm{~mL})$ for 9 min under sonication (450 Watts) and then was kept overnight under mechanical agitation at room temperature. The modified magnetite was washed once with ethanol using magnetic decantation and dried at room temperature.

\subsection{Synthesis of Ugi-magnetic-composite (UMC)}

Aldehyde-modified magnetite $(0.08 \mathrm{~g})$ dispersed in $2 \mathrm{~mL}$ chloroform/methanol (1:2 v/v mixture) was reacted with appropriate amount of bis-amine PEG $(0.15 \mu \mathrm{Mol})$ overnight at room temperature under nitrogen atmosphere and stirring (Modify-aldehyde magnetite/ bis-amine PEG molar ratio $=1: 5$ ). The protonated imine formed was reacted with PLA $(0.029 \mu \mathrm{Mol})$ and tert-butyl isocyanide $(0.029 \mu \mathrm{Mol})$ at room temperature for 72 hours under nitrogen atmosphere and stirring (aldehyde-modified mag- netite/bis-amine PEG/PLA/tert-butyl isocyanide molar ratio equal to $1 / 5 / 5 / 1$, respectively). After this time, the product obtained was washed once with ethanol using magnetic decantation and dried at room temperature.

\subsection{Preparation of magnetic microsphere}

Magnetic microspheres were prepared using the single emulsion-solvent evaporation methodology [39], with some modifications. Briefly, the UMC $(100 \mathrm{mg})$ was dispersed in $1 \mathrm{~mL}$ of dichloromethane. Soon afterwards, the prepared UMC dispersion was added to a beaker containing $5 \mathrm{~mL}$ of cold PVA (w/w $0.5 \%$ ). This system was kept under stirring at $20000 \mathrm{rpm}$ during 5 minutes. Then, the o/w emulsion was poured into a beaker containing $50 \mathrm{~mL}$ of PVA (w/w $0.1 \%$ ) and kept under mechanical stirring for 2 hours at room temperature $\left(25^{\circ} \mathrm{C}\right)$ to harden the microspheres by solvent evaporation. Magnetic microspheres were then collected by centrifugation at $2500 \mathrm{rpm}$ and washed 3 times with distilled water. Finally, the collected magnetic microspheres were freeze-dried by lyophilization and stored at $12{ }^{\circ} \mathrm{C}$.

\subsection{Materials characterizations}

\subsubsection{Hydrogen-1 nuclear magnetic resonance}

Mmeasurements of PLA and bis-amine PEG were carried out in a Varian Mercury VX-300 NMR spectrometer operating at $300 \mathrm{MHz}\left({ }^{1} \mathrm{H}\right)$ and $75 \mathrm{MHz}$ $\left({ }^{13} \mathrm{C}\right)$. Samples $(15$ or $50 \mathrm{mg}$ ) were dissolved in chloroform-D1 $(0.8 \mathrm{~mL})$ in $5 \mathrm{~mm}$ NMR tubes at room temperature.

\subsubsection{Gel permeation chromatography}

Measurements of PLA and bis-amine PEG were determined using an Agilent 1200 series HPLC with a MIXED-C column. Chloroform was used as the solvent with a flow rate of $1.0 \mathrm{~mL} / \mathrm{min}$ and polystyrene was used as a standard.

\subsubsection{Fourier transform infrared}

Spectra of PLA, bis-amine PEG and aldehyde-modified magnetite was performed using a Varian model 3100 FTIR Excalibur Series spectrophotometer (Japan). Samples were macerated with potassium bromide (1 mg/100 mg samples/KBr). Then, the FTIR spectra of the samples were recorded at room temperature and a resolution of $4 \mathrm{~cm}^{-1}$. 


\subsubsection{Differential scanning calorimetry}

Measurement of PLA, bis-amine PEG, magnetite, aldehyde-modified magnetite and UMC was carried out with help of the TA Q1000 V9.9 build 303 Calorimeter. Briefly, $5 \mathrm{mg}$ of the samples were heated and cooled at a rate of $10^{\circ} \mathrm{C} / \mathrm{min}$ from -80 to $200^{\circ} \mathrm{C}$ under nitrogen flow. Values of glass transition $\left(T_{\mathrm{g}}\right)$, melting temperature $\left(T_{\mathrm{m}}\right)$ and the crystallization temperature on cooling $\left(T_{\mathrm{cc}}\right)$ were taken in a cooling run after the second heating run.

\subsubsection{Thermogravimetric analyses}

Were performed using a TA TGA Q500 Thermoanalyser. Measurements were carried out in nitrogen at a heating rate of $20^{\circ} \mathrm{C} / \mathrm{min}$ up to $700^{\circ} \mathrm{C}$ with a gas flow rate of $20 \mathrm{~mL} / \mathrm{min}$.

\subsubsection{X-ray diffraction}

Measurement of bis-amine PEG, magnetite, aldehyde-modified magnetite and UMC was determined in Rigaku Miniflex X-ray diffractometer in a $2 \theta$ range from 20 to $70^{\circ}$ by the FT (fixed time) method. The steps used were equal to $0.05^{\circ}$ and a time of $1 \mathrm{~s}$, using a tube voltage and current equal to $40 \mathrm{kV}$ and $20 \mathrm{~mA}$, respectively. The radiation used was $\mathrm{CuK} \alpha=1.5418 \AA$.

\subsubsection{Magnetic force}

Measurement of magnetite, aldehyde-modified magnetite and UMC were performed as reported by our group elsewhere [40]. Briefly the samples were kept under a variable magnetic field (0-790 Gauss), calibration of the test was performed by using reduced $\mathrm{Fe}, \mathrm{CoSO}_{4} \cdot 7 \mathrm{H}_{2} \mathrm{O}$ and $\mathrm{CuSO}_{4} \cdot 5 \mathrm{H}_{2} \mathrm{O}$ as standard for high level, medium level and a lack of magnetic force, respectively [41-43]. Then, the apparent variation in the mass of the sample in the presence of a magnetic field was calculated subtracting the mass of the sample in the presence of a magnetic field from the mass of sample.

\subsubsection{Scanning electron microscopy}

Measurement of magnetite, UMC and magnetic microspheres was carried out with a JEOL JSM5610 LV microscope, using acceleration voltage of $15 \mathrm{kV}$. Samples were coated with gold in order to study the morphology of the magnetic particles synthesized by UFCC. The materials were sampled by taking several images of various magnifications to ensure that analysis was based on a representative region of the sample.

\subsubsection{Magnetic induction hyperthermia}

MIH measurements of magnetic microspheres were performed using the Ambrell Easy Heat machine model L1. Samples, dispersed in distilled water (10 and $20 \mathrm{mg} / \mathrm{mL}$ at $25^{\circ} \mathrm{C}$ ), were thermally isolated using glass fiber textile. Soon afterwards, each sample was inserted inside the coil of the machine. Electrical current equal to 200, 400 and 600 A were applied for $600 \mathrm{~s}$. Sample temperature was recorded at $120,240,360,480$ and $600 \mathrm{~s}$. The bulk temperature of the samples was measured before and after the induction heating tests.

\section{Results and discussion}

The Ugi reaction allows the binding, in a single experimental step, of four functional groups: amine, aldehyde, carboxylic acid and isocyanide [37]. In this work, we placed these functional groups as follows:

I. PEG provided the amine group. Instead of using a commercial diamine reagent, PEG was modified so that the amine group is attached to the polymer backbone by labile bond (i.e., amide). This labile link could permit the release of PEG and/or any molecule bound to the free end.

II. Iron particles were coated with aldehyde groups. This choice was based on the ease of modification of the NP with glutaraldehyde.

III. Obviously, the carboxylic group was supplied by the PLA.

IV. A commercial reagent was used as tert-butyl isocyanide. However, this could be replaced by some interesting molecules in future applications.

\subsection{Synthesis of diamine PEG}

Firstly, PEG was modified by a known method [44, 45], which is based on the reaction of the hydroxyl groups of the polymer with ethylenediamine in the presence of CDI [46]. However, yields were small (Table 1). Possibly due to the various purification steps necessary to remove excess CDI. To improve yields, another linker was used to attach the ED: chlorate monochlorated acetyl. In this reaction, further purification steps were not necessary after the synthesis of Product 1 (see Figure 1), due to the easy elimination of the hydrochloric acid during the 
<smiles>O=C(Cl)CCOCCOCCOC(=O)CCl</smiles>

(1)

(1)

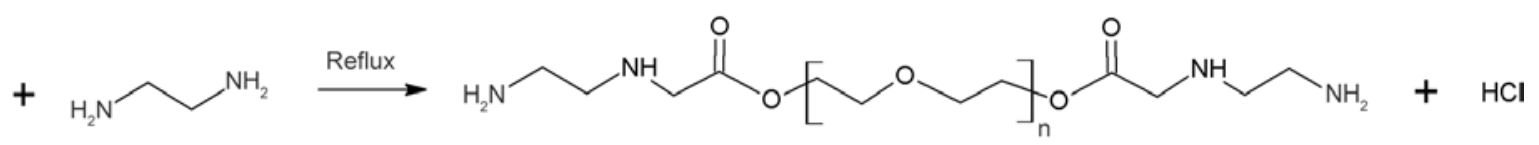

(2)

Figure 1. Synthesis of PEG bis-amine by chlorate monochlorated acetyl/carbinyldiimidazole reaction

Table 1. Yields of poly (ethyleneglycol) bis amine functionalized $(p<0.01)$

\begin{tabular}{|c|l|c|c|c|}
\hline Samples & \multicolumn{1}{|c|}{ Method } & $\begin{array}{c}\text { Yield } \\
{[\%]}\end{array}$ & SD $^{*}$ & $\mathbf{C V}^{* * *}$ \\
\hline PEG bis amine 1 & Via CDI/ED & 71.7 & 1.5 & 2.1 \\
\hline PEG bis amine 2 & Via CCA/ED & 94.3 & 1.2 & 1.2 \\
\hline
\end{tabular}

*Standard Deviation

${ }^{* *}$ Variation coefficient

acetylation. On the other hand, the residual CCA remaining after refluxing was eliminated by ethanol esterification. The formed ester was easily eliminated because it was miscible with the solvent used for the synthesis and purification of bis-amine PEG [47]. Moreover, the cross-link reactions, on both sides of PEG, were avoided using a small excess of ethylenediamine.

The yields of this reaction were significantly increased, as shown in Table 1, as expected due to there being fewer purification steps required.

As shown in Table 1, the mechanism of CDI/ED presented moderate yields, probably due to several purifications steps being required to eliminate the residual CDI before the amine reaction. However, these results are in agreement with those reported for the functionalization of PEG with CDI [48]. On the other hand, high yields (94.3\%) were achieved for $8 \mathrm{~h}$ reaction at room temperature with $\mathrm{CCA} / \mathrm{ED}$; it was not necessary to perform purification of activated PEG with CCA before the amine reaction.

The products (1) and (2) of the Figure 1 were characterized by NMR ${ }^{1} \mathrm{H}$ and FTIR and the spectra obtained are shown in Figures 2 and 3, respectively. It can be seen in Figure 2a that only two peaks at 4.11 and $3.65 \mathrm{ppm}$ appear, which are assigned as $\left(\mathrm{CH}_{2} \mathrm{Cl}\right)$ and ethylene $\left(\mathrm{CH}_{2}-\mathrm{CH}_{2}\right)$ groups of CCA and PEG, respectively [49]. Consequently, the ${ }^{1} \mathrm{H}-\mathrm{NMR}$ spectra of aminated PEG (Figure $2 b$ ) retained the peak at $3.65 \mathrm{ppm}$ assigned to $\left(\mathrm{CH}_{2}-\mathrm{CH}_{2}\right)$ of $\mathrm{PEG}$ and to $\left(\mathrm{CH}_{2} \alpha \mathrm{C}=\mathrm{O}\right)$; however, Figure $2 \mathrm{~b}$ allows us to infer the absence of the peak assigned to $\mathrm{CH}_{2} \mathrm{Cl}$ groups of CCA. These protons might appear overlapped by the signal of $\left(\mathrm{CH}_{2}-\mathrm{CH}_{2}\right)$ groups of $\mathrm{PEG}$ due to the release of chloride group after the amination process, which suggests the success of the amination process. Unfortunately, we cannot observe the peaks assigned to the ethylene $\left(\mathrm{CH}_{2}-\mathrm{CH}_{2}\right)$ groups of ethylenediamine, probably due to their overlap with the ethylene $\left(\mathrm{CH}_{2}-\mathrm{CH}_{2}\right)$ groups of PEG.

FTIR spectra of activated and aminated PEG showed the characteristic absorption bands of this product, i.e. the stretching band at 1751 and $1730 \mathrm{~cm}^{-1}$ related to $\mathrm{C}=\mathrm{O}$ of ester groups of activated and aminated PEG, respectively (see Figure 3). Axial bending at $3420 \mathrm{~cm}^{-1}$ is related to the $\mathrm{N}-\mathrm{H}$ of amine groups of aminated PEG (see Figure 3 curve b). Unfortunately, the absorption band characteristic of amine groups like $\mathrm{C}-\mathrm{N}$ bounds could not be observed, probably due to the small molar range of amine groups in relation to PEG.

\subsection{Synthesis of PLA}

Low molecular weight PLA was synthesized by onestep autocatalytic polycondensation of the lactic acid. This procedure does not need further purification steps to eliminate the catalytic agent; in this case, the purification process was performed to ensure the elimination of low molecular weight oligomers [50]. The synthesized PLA was characterized by FTIR; the results are shown in Figure 4.

The FTIR spectra of PLA homopolymers, shown in Figure 4, present the characteristic absorption bands of this polymer [51], i.e., an axial bending at $3518 \mathrm{~cm}^{-1}$ corresponding to $\mathrm{O}-\mathrm{H}$ groups, axial bending at 2997 and $2946 \mathrm{~cm}^{-1}$ related to $\mathrm{CH}$ and $\mathrm{CH}_{3}$, a stretching band at $1757 \mathrm{~cm}^{-1}$ corresponding to $\mathrm{C}=\mathrm{O}$ groups, asymmetric and symmetric deformation vibrations at 1486 and $1464 \mathrm{~cm}^{-1}$ of the $\mathrm{CH}_{3}$ groups, a stretching band at $1271 \mathrm{~cm}^{-1}$ of $\mathrm{C}-\mathrm{C}=\mathrm{O}$ groups, stretching bands at $1196,1134,1093 \mathrm{~cm}^{-1}$ related to $\mathrm{C}-\mathrm{O}$ groups, a stretching band at $1046 \mathrm{~cm}^{-1}$ of $\mathrm{O}-\mathrm{H}$ 


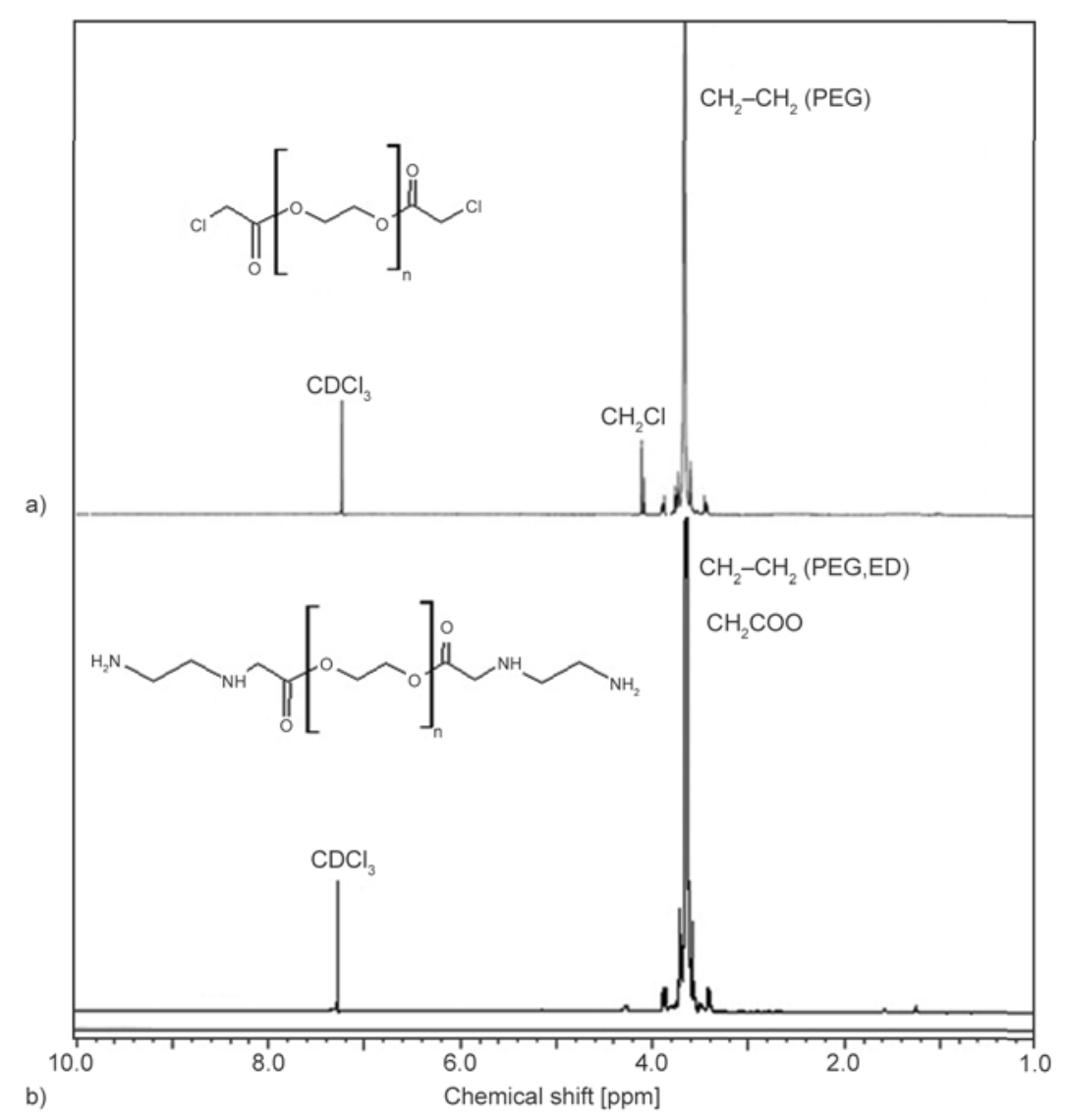

Figure 2. ${ }^{1} \mathrm{H}-\mathrm{NMR}$ spectra of activated PEG (a) and aminated PEG (b)

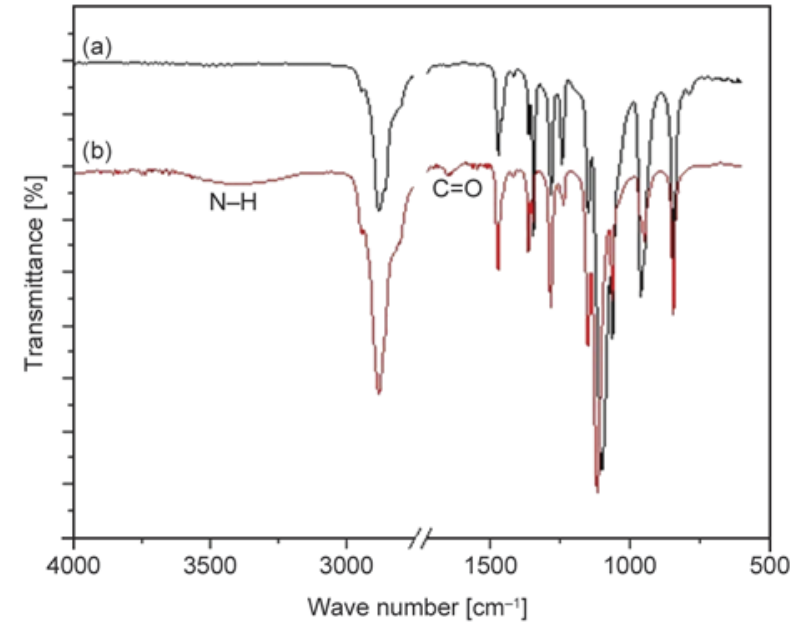

Figure 3. FTIR spectra of activated PEG (a) and FTIR of aminated PEG (b)

groups, stretching bands at 875 and $789 \mathrm{~cm}^{-1}$ related to $\mathrm{C}-\mathrm{C}$ groups and a stretching band at $704 \mathrm{~cm}^{-1}$ of the $\mathrm{O}-\mathrm{H}$ group; these are all in agreement with those reported in the literature [10, 52].

In turn, the synthesized PLA were characterized by ${ }^{1} \mathrm{H}-\mathrm{NMR}$ and ${ }^{13} \mathrm{C}-\mathrm{NMR}$, shown in Figures 5 and 6, respectively.

Figure 4 shows the ${ }^{1} \mathrm{H}$-NMR spectra of the PLA homopolymers. It can be clearly seen from Figure 5

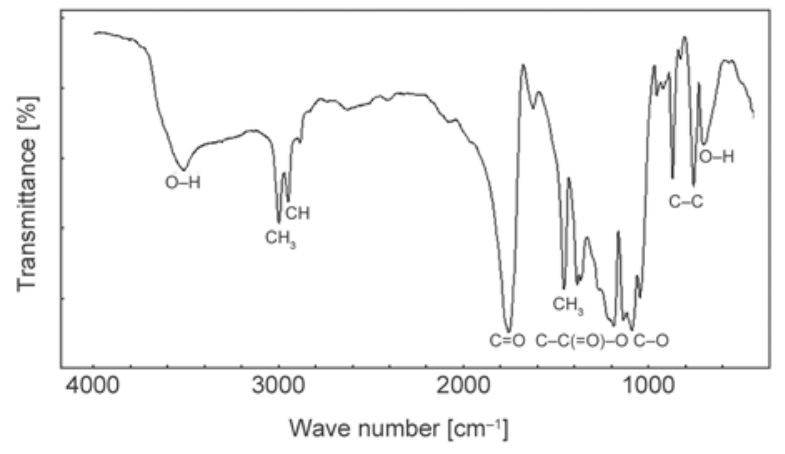

Figure 4. FTIR spectra of synthesized PLA

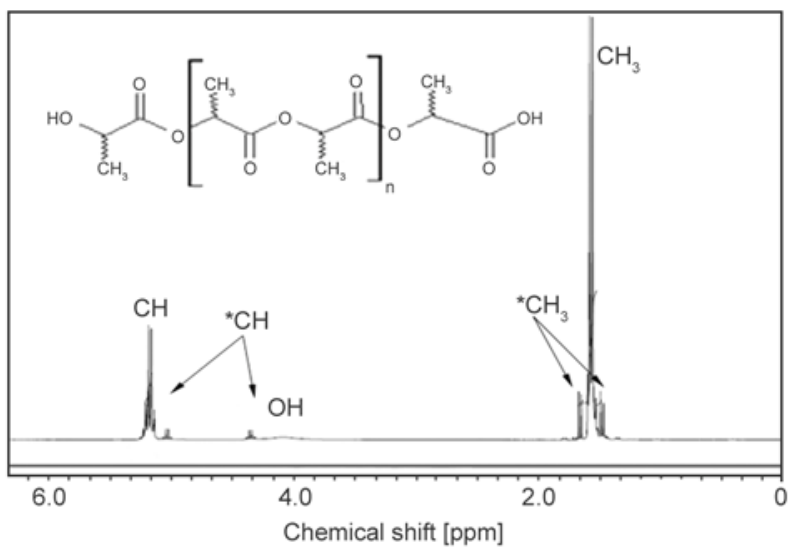

Figure 5. ${ }^{1} \mathrm{H}-\mathrm{NMR}$ spectra obtained for sample of the PLA homopolymer 


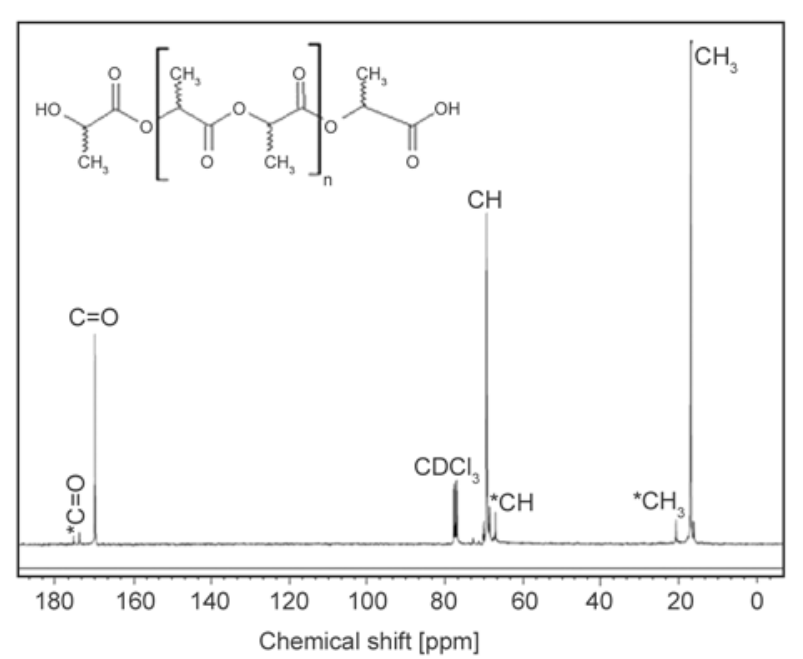

Figure 6. ${ }^{13} \mathrm{C}$-NMR spectra obtained for samples of the PLA homopolymers

Table 2. Molecular weights of synthesized poly(lactic acid)

\begin{tabular}{|c|c|c|c|}
\hline Samples & $\begin{array}{c}\boldsymbol{M}_{\mathbf{w}} \\
{\left[\mathbf{g} \cdot \mathbf{m o l}^{-\mathbf{1}} \mathbf{]}\right.}\end{array}$ & $\begin{array}{c}\boldsymbol{M}_{\mathbf{n}} \\
{\left[\mathbf{g} \cdot \mathbf{m o l}^{-\mathbf{1}} \mathbf{]}\right.}\end{array}$ & $\boldsymbol{M}_{\mathbf{w}} / \boldsymbol{M}_{\mathbf{n}}$ \\
\hline PLA1 & 6543 & 4641 & 1.41 \\
\hline PLA2 & 6475 & 4466 & 1.45 \\
\hline PLA3 & 6287 & 4428 & 1.42 \\
\hline
\end{tabular}

that only two peaks at 1.49 and 5.16 ppm appear, which are assigned to the methyl $\left(\mathrm{CH}_{3}\right)$ and methine (CH) signals from the PLA homopolymer, respectively [53]. These results are consistent with those obtained from PLA homopolymers prepared by the polycondensation of lactic acid [54]. Furthermore, Figure 6 shows three peaks at 16.92, 69.35 and $169.83 \mathrm{ppm}$ which are assigned to the methyl $\left(\mathrm{CH}_{3}\right)$, methine $(\mathrm{CH})$ and carbonyl $(\mathrm{C}=\mathrm{O})$ groups, respectively. The peaks that appear at 1.47, 1.65, 4.34, and $5.14 \mathrm{ppm}$ (see Figure 5) and 20.71, 67.77, and $17383 \mathrm{ppm}$ (see Figure 6) were assigned to the Dlactic acid product present in the samples $[55,56]$. The number-average molecular weights $\left(M_{\mathrm{n}}\right)$ and polydispersities $\left(M_{\mathrm{w}} / M_{\mathrm{n}}\right)$ obtained from GPC are listed in Table 2.

Three batches of PLA were prepared by the method described in this work. Analysis by GPC (Table 2) showed good batch-to-batch reproducibility (Variant coefficient $\approx 2 \%$ ). The polymers obtained presented molecular weight values suitable for use in controlled release systems [57]. Furthermore, a narrow $M_{\mathrm{w}} / M_{\mathrm{n}}$ allows greater control of the release profiles [58].

\subsection{Synthesis of aldehyde-modified magnetite}

Glutaraldehyde modification of the magnetite obtained by co-precipitation [38] was studied by

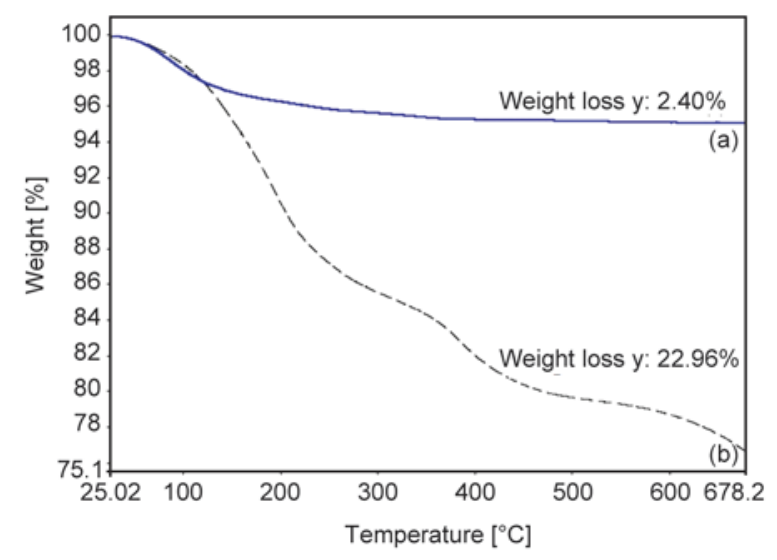

Figure 7. Thermogravimetric analysis of magnetite (a) and aldehyde-modified magnetite (b)

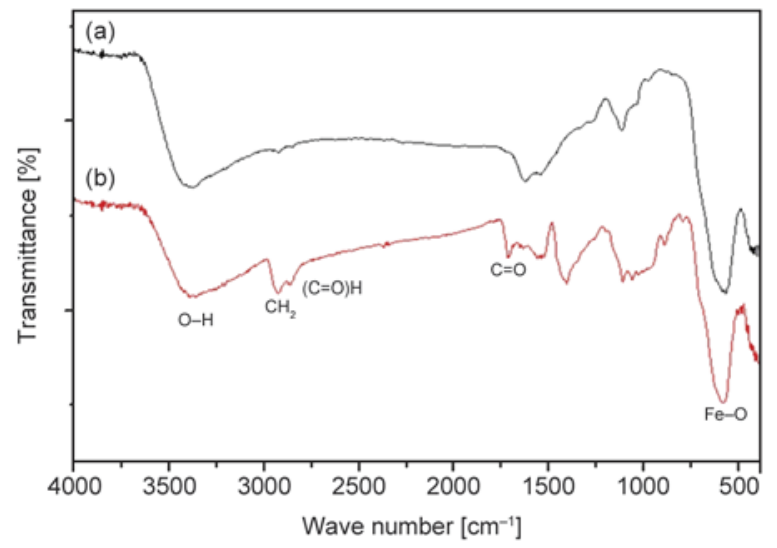

Figure 8. FTIR spectra of magnetite 7 (a) and aldehydemodified magnetite 7 (b)

thermogravimetric analysis; the results obtained are shown in Figure 7.

The comparison between weight losses up to $600{ }^{\circ} \mathrm{C}$ of magnetite and modified product, equal to $2.0 \%$ (due to water loss) and $22.9 \%$, respectively, demonstrated the presence of the aldehyde.

Aldehyde modification of magnetite was also confirmed by FTIR analyses, as can be seen in Figure 8 .

The FTIR spectrum of magnetite provides information about the excitation of vibration or rotation of molecules in their ground electronic state. In the magnetite structure presented in Figure 8 curve a, these vibrations are associated with the stretching deformation of the interatomic bond of iron with other molecules like oxygen and appears at 588 and $585 \mathrm{~cm}^{-1}$ $[59,60]$. The FTIR analysis of aldehyde-modified magnetite (Figure 8 curve b) also showed the presence of aldehyde groups by the appearance of stretching bands at $1717 \mathrm{~cm}^{-1}$ related to $\mathrm{C}=\mathrm{O}$ of ester groups, axial bending at $2860 \mathrm{~cm}^{-1}$ related to $(\mathrm{C}=\mathrm{O}) \mathrm{H}$ of the aldehyde group and axial bending at $2927 \mathrm{~cm}^{-1}$ corresponding to the $\mathrm{CH}_{2}$ of aldehyde groups. 


\subsection{Synthesis of Ugi magnetic composite}

Ugi as well as Passerini reactions are classified as isocyanide-based multicomponent reactions. The Ugi reaction is usually performed in a polar protic solvent such as methanol, and some success in water was recently showed [61]. In turn, non-polar halogenated solvents favoring the occurrence of the Passerini reaction, since most of the amines are insoluble in cited media [62]. Thus, the synthesis of the magnetic composite was performed in dichloromethane $/ \mathrm{MeOH}$. This medium as chosen due to the heterogeneous nature of the Ugi components. In addition, the bis-amine PEG is soluble in dichloromethane, allowing its use in the Ugi reaction. This way, the Ugi reaction is favored in comparison with Passerini reaction as shown in Figure 9. The yield of the magnetic composite synthesis was equal to $80 \%$, determined by the weight of the final product. Obtained material was characterized by TGA and the main results are shown in Table 3.

Table 3 shows the decrease of the $T_{\mathrm{g}}, T_{\mathrm{c}}$ and $T_{\mathrm{m}}$ of UMC in comparison to PLA. The replacement of the rigid homogeneous PLA-PLA interaction by heterogeneous PLA-PEG interaction in the UMC makes the macromolecular motion easier, producing the observed decrease of the temperature in the cited transitions (see Figure 10a). As a consequence, the UMC exhibited values of $T_{\mathrm{g}}\left(52.8^{\circ} \mathrm{C}\right)$ that were lower than those for PLA, equal to 52.8 and $59.8^{\circ} \mathrm{C}$, respectively (see Table 3 ). These results are in agree-

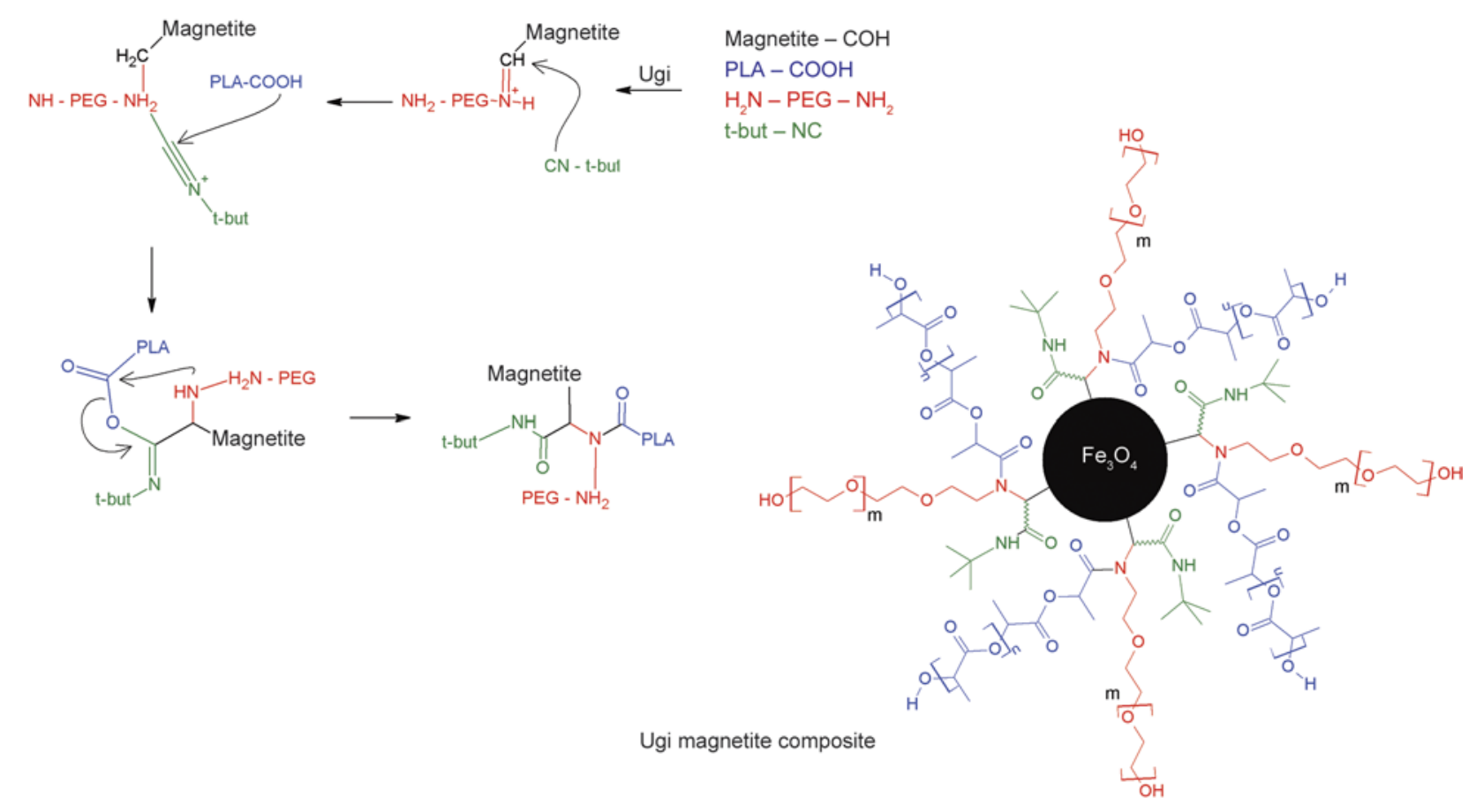

Figure 9. Syntheses of magnetic composite by Ugi four component condensation sheme of Ugi magnetic particle
Table 3. TGA analyses of carboxylic PLA, aminated PEG and Ugi magnetic composite

\begin{tabular}{|l|c|c|r|c|c|}
\hline \multicolumn{1}{|c|}{ Sample } & $\begin{array}{c}\boldsymbol{T}_{\mathbf{g}} \\
{\left[{ }^{\circ} \mathbf{C}\right]}\end{array}$ & $\begin{array}{c}\boldsymbol{T}_{\mathbf{c c}} \\
{\left[{ }^{\circ} \mathbf{C}\right]}\end{array}$ & $\begin{array}{c}\boldsymbol{T}_{\mathbf{m}} \\
{\left[{ }^{\circ} \mathbf{C}\right]}\end{array}$ & $\begin{array}{c}\boldsymbol{X}_{\mathbf{c}} \\
{[\mathbf{\%}]}\end{array}$ & $\begin{array}{c}\boldsymbol{T}_{\mathbf{d}}{ }^{*} \\
{\left[{ }^{\circ} \mathbf{C}\right]}\end{array}$ \\
\hline PLA & 59.8 & 98.6 & 144.0 & 21.2 & 272.8 \\
\hline PEG-NH & - & - & 56.7 & - & 394.1 \\
\hline UMC & 52.8 & 84.2 & $\begin{array}{r}140.3 \\
123.2 \\
54.4\end{array}$ & 29.2 & 264.4 \\
& & & 592.4 \\
\hline
\end{tabular}

Determined considering $\Delta H_{\mathrm{m}}^{0}=106 \mathrm{~J} / \mathrm{g}[85]$.

ment with those previously reported for the decreased values of $T_{\mathrm{g}}$ in some PLA-PEG copolymers [63]. The influence of PEG on the crystallization behavior of UMC is also shown in Table 3. From this table, it was observed that the $T_{\mathrm{c}}$ of PLA decreased significantly with the incorporation of PEG (reduction around $15^{\circ} \mathrm{C}$ ). Similar results were reported for the $T_{\mathrm{c}}$ behavior of PLA-PEG copolymers [64]. The melting behavior is also influenced by the incorporation of PEG into PLA. It was clearly evident from Table 3 that there was a decrease in the $T_{\mathrm{m}}$ of between 14 and $21^{\circ} \mathrm{C}$ in the case of UMC. This decrease in the melting point is also an indication of the formation of a composite (Figure 8 curve b) [65]. The degree of crystallinity increased from 21.2 to $29.2 \%$ in the case of UMC, suggesting that $X_{\mathrm{c}}$ increased in the case of UMC with an increase of the $\Delta H_{\mathrm{m}}$. In turn, the increased crystallinity in the PLA-PEG copolymer was previously reported [66]. It could be con-
${ }^{*}$ Degradation temperature determined by TGA 
cluded that PEG has the ability to increase flexibility of the UMC material by increasing the mobility of the PLA molecule [16]. On the other hand, only two temperatures for weight loss appeared, at 264.4 and $392.4{ }^{\circ} \mathrm{C}$ (see Table 3 and Figure 10c), for the Ugi magnetic composite, which probably belong to the PLA and PEG molecule, respectively. The increase of the polymer chains mobility in the UMC material can decrease the thermal stability of the material. In addition, this phenomenon could be enhanced by the presence of basic amines from the residual bis-amine PEG. Moreover, the residue in the case of UMC was negligible. Therefore, these results are in agreement with those that have been previously reported [67].

In addition, the chemical linkage between PEG, PLA and magnetite could be confirmed by the FTIR spectra of Ugi magnetite composite (Figure 11).

In Figure 11, the absorption bands of PEG and PLA linked to magnetite are clearly seen; i.e., axial bending at $2945 \mathrm{~cm}^{-1}$ related to $\mathrm{CH}_{2}$ of the ether groups and axial bending at $1093 \mathrm{~cm}^{-1}$ corresponding to $\mathrm{C}-\mathrm{O}$ of ether groups, which are assigned to PEG. The stretching band at $1762 \mathrm{~cm}^{-1}$ related to $\mathrm{C}=\mathrm{O}$ of ester groups, axial bending at $2996 \mathrm{~cm}^{-1}$ corresponding to $\mathrm{CH}_{3}$ and the stretching band at $1048 \mathrm{~cm}^{-1}$ were related to $(\mathrm{C}=\mathrm{O})-\mathrm{O}-\mathrm{C}$ of the ester groups, which were assigned to PLA. Finally, the FTIR spectra also presented the stretching absorption bands of magnetite at 588 and $585 \mathrm{~cm}^{-1}$ described above.

Magnetic composites were also characterized by $\mathrm{XRD}$, the results of which are shown in Figure 12.

XRD results from magnetite, magnetite modified with aldehyde and magnetic composite are shown in Figures 12 curves a)-c) respectively. All the tested materials present peaks at $2 \theta$ equal to $30.3^{\circ}$, $35.7^{\circ}, 43.3^{\circ}, 53.9^{\circ}, 57.3^{\circ}$ and $63.0^{\circ}$, which confirm the spinel structure of the crystal, characteristic of this iron oxide [68], proving that Ugi four component condensation does not change the particles' nature [40, 27, 69]. Moreover, the crystal size of magnetic particles was calculated by the Scherrer equation [70]. Crystal size values of 13.6, 13.4 and $12.5 \mathrm{~nm}$ were obtained for magnetite, aldehydemodified magnetite and Ugi magnetic composite particles, respectively. This nanometric size could provide superparamagnetic properties for the Ugimodified magnetic particles [71] making them very interesting for studies of nano-carriage, targeting and magnetic hyperthermia $[22,72,73]$.

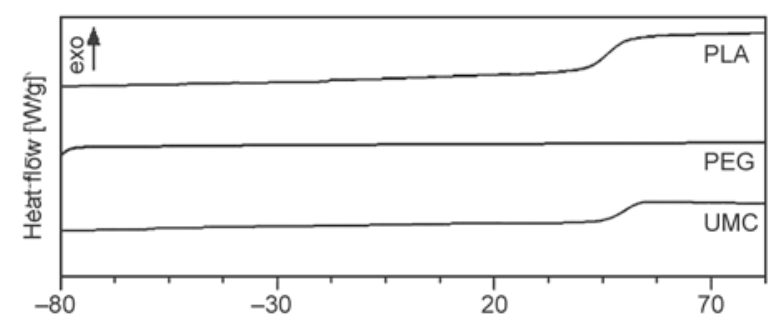

a) Temperature $\left[{ }^{\circ} \mathrm{C}\right]$
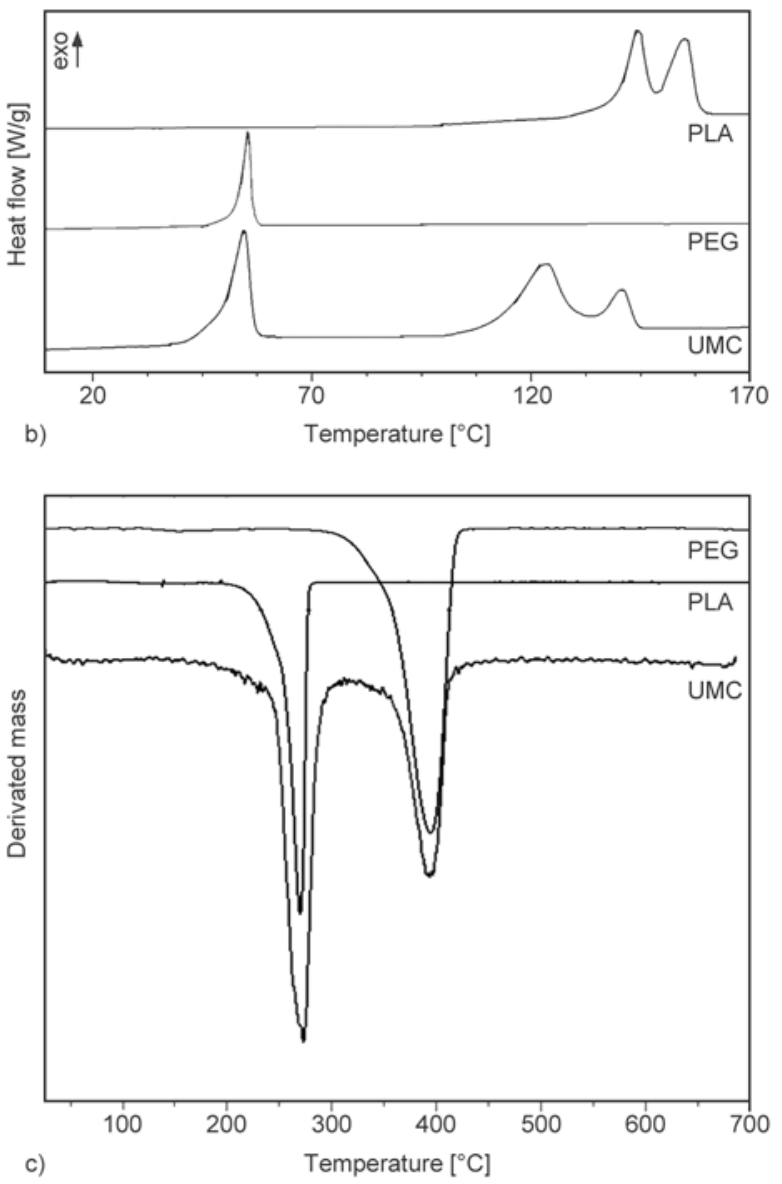

Figure 10. DSC thermograms of PLA, PEG and it magnetic Ugi composite, $T_{\mathrm{g}}(8 \mathrm{a})$ and $T_{\mathrm{m}}(8 \mathrm{~b})$. TGA curves for PLA, PEG and UMC (8c).

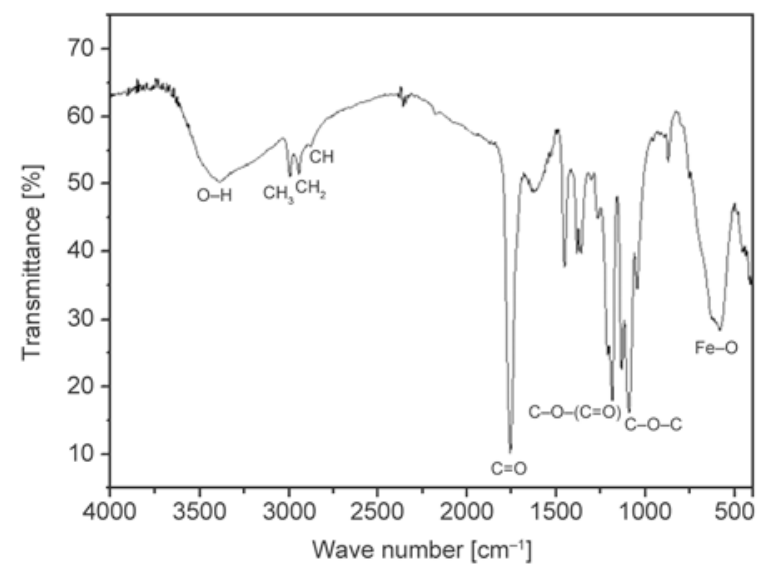

Figure 11. FTIR spectra of Ugi magnetic composite 


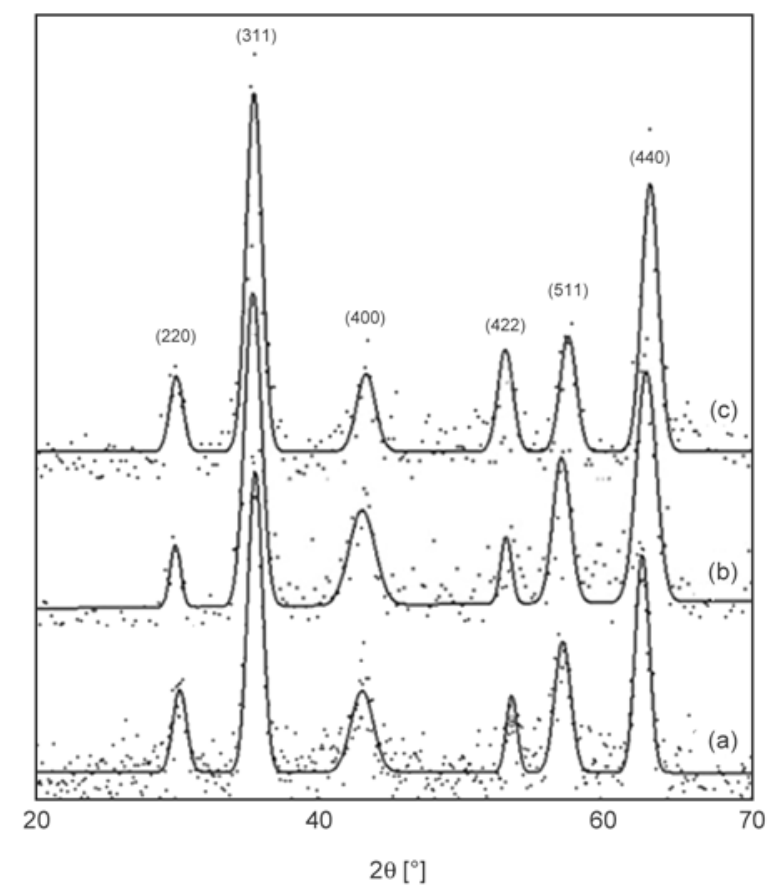

Figure 12. XRD analyses of magnetite 10a, aldehyde magnetite $10 \mathrm{~b}$ and Ugi magnetic composite 10c

The magnetic products obtained were also characterized by magnetic force tests, the results of which are shown in Table 4 and Figure 13.

As expected, the chemical modification of magnetite and its covalent linkage to PEG and PLA by Ugi four component condensation decreased the values of magnetic force of the composite $[40,74$, 75] when compared to free magnetite and aldehyde magnetite. These results are in agreement with those reported for the organic modification of magnetite [76-78].

Taking into account that the crystalline structure of magnetite remains unchanged after Ugi modifica-

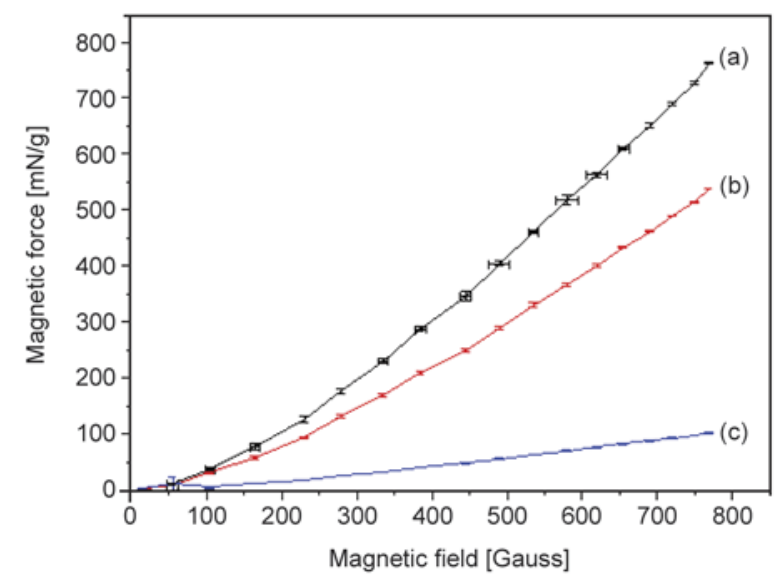

Figure 13. Magnetic force of magnetite (a), aldehyde magnetite (b) and Ugi magnetic composite at 800 Gauss (c)
Table 4. Magnetic force of magnetite, aldehyde magnetite and Ugi magnetic composite

\begin{tabular}{|l|c|c|}
\hline \multicolumn{1}{|c|}{ Samples } & $\begin{array}{c}\text { MF } \\
{[\mathbf{m N} / \mathbf{g}]}\end{array}$ & $\begin{array}{c}\text { Relative MF } \\
\text { [\%] }\end{array}$ \\
\hline Magnetite & $762.89 \pm 1.20$ & - \\
\hline Aldehyde magnetite & $589.10 \pm 0.74$ & $<29.33$ \\
\hline Ugi magnetic composite & $103.14 \pm 1.20$ & $<86.48$ \\
\hline
\end{tabular}

MF: magnetic force

tion, this decrease in the magnetic force of composite is due to the presence of the organic phase on magnetite; this result is in complete agreement with that of TGA.

Morphology of non-modified magnetite, modified magnetite bonded to PLA and PEG by UFCC and magnetic microspheres was characterized by the scanning electron microscopy technique; the results are shown in Figure 14.

Figure 14 shows the morphological change of magnetite after Ugi four component reaction with PEG and PLA. The particles of pure magnetite (see Figures $14 \mathrm{a}$ and $14 \mathrm{~b}$ ) present a smooth surface. On the other hand, the UFCC-modified magnetic particles (see Figure 14c and 14d) presented a different morphology, with an increase of the surface roughness due to the new organic phase bound to the magnetite particles, confirming the success of the chemical modification of magnetite with PEG and PLA by UFCC. In addition, Figure 14e clearly shows that $\mathrm{UMC}$ is able to form magnetic microspheres of PLA/PEG/magnetite after the single emulsion-solvent evaporation procedure. The surface structure of all microspheres possesses large pores, which probably influence the amount of PEG linked by UFCC. The ability of PEG to form small pores in the surfaces of the microspheres was reported for microparticles based on blends of PLGA/PLA and PEG and also applies to microparticles composed of diblock polymer [79]. During the precipitation step, the PEG branches of the diblock copolymer orientated toward the internal and surrounding aqueous phase and formed a sponge-like structure [80].

Finally, the heating experiments in AC magnetic field were performed on a medium frequency induction heating apparatus. Figure 15 show the temperature of the samples as function of the electrical current and time. Magnetic PLA-PEG/magnetite microspheres were tested using two concentrations, equal to 10 and $20 \mathrm{mg} / \mathrm{mL}$. All the tests were started at $25^{\circ} \mathrm{C}$. As one can see, the reached temperature is directly related to the used concentration, electrical 


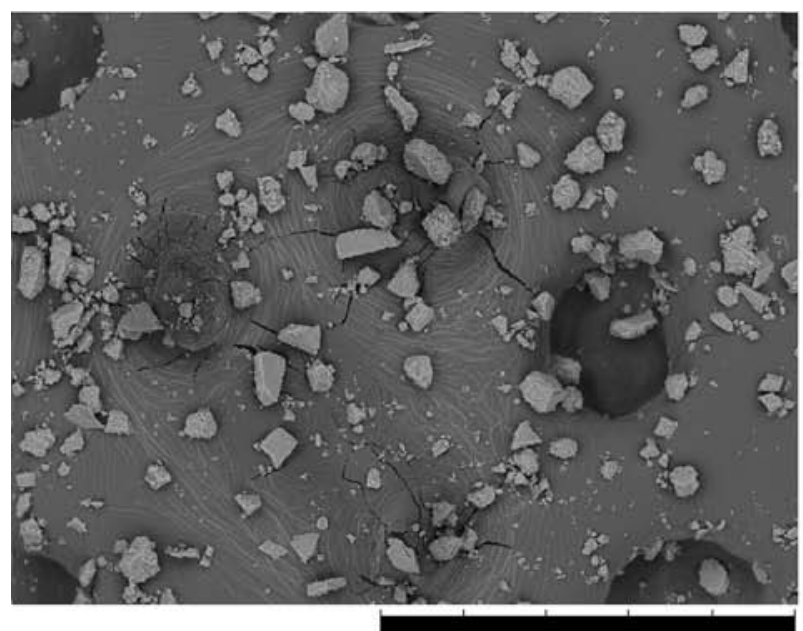

Magnetite

a)

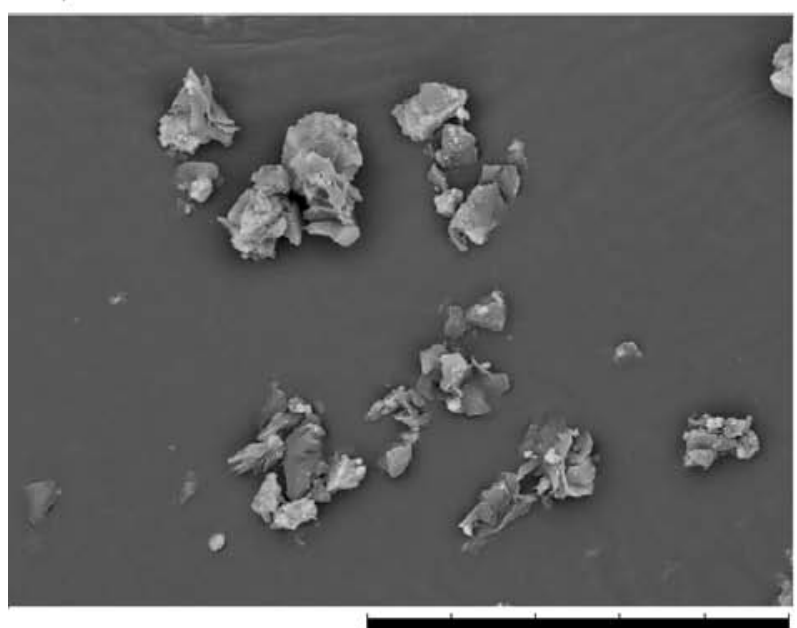

UMC

c)

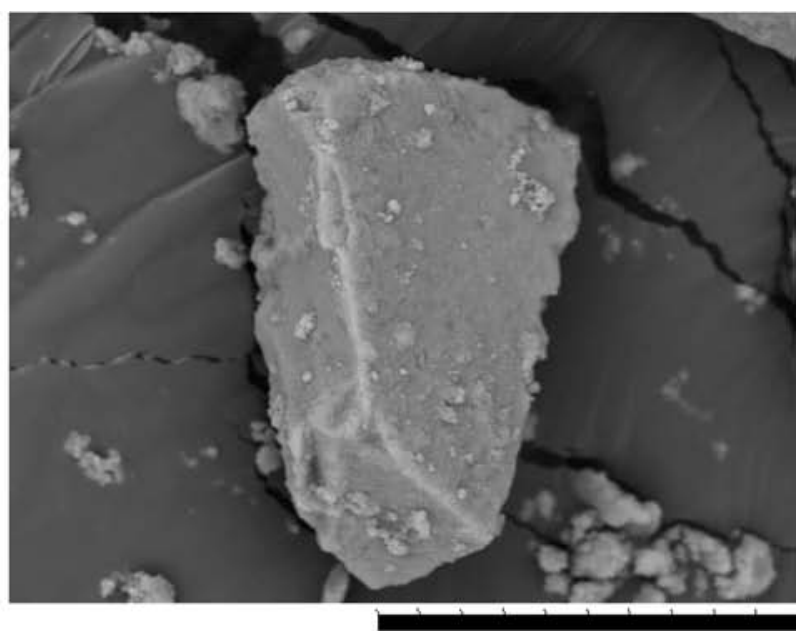

$5 \mu \mathrm{m}$

b)

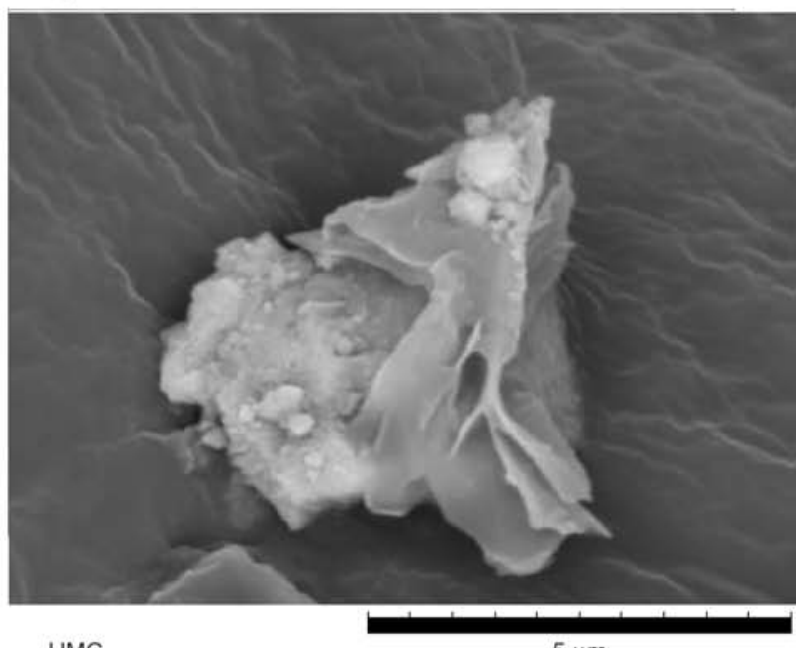

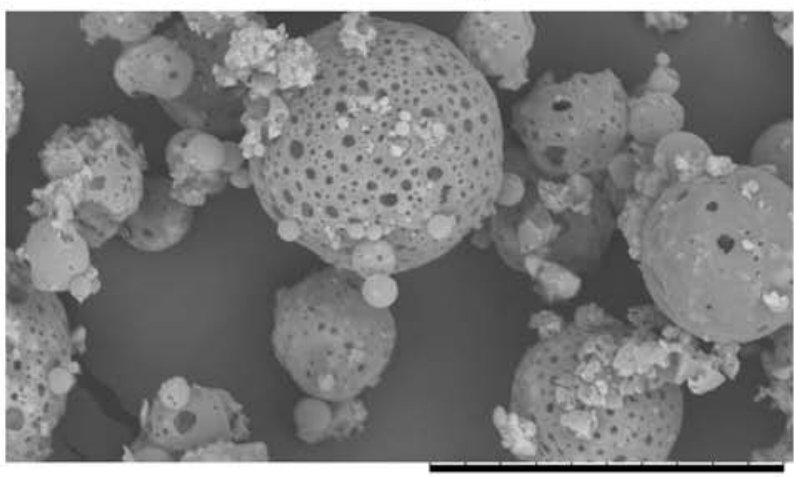

Magnetic microspheres

e)

$30 \mu \mathrm{m}$

Figure 14. Scanning electron microscopy of magnetite (a and b) and Ugi-magnetic-composite (c and d), magnetic microspheres of PLA/PEG/magnetite (e)

current and time. The use of the highest current values produced the highest temperatures. Thus, the heating effect could be controlled by adjusting the value of the apparent current $[28,81,82]$. In addition, in the best cases, achieved using $600 \mathrm{~A}$, the temperature of samples with concentrations equal to 10 and $20 \mathrm{mg} / \mathrm{mL}$ increased from 25 to 37.7 and $47.1^{\circ} \mathrm{C}$, respectively. Similar results were obtained from hypertermic evaluation of particles based on biodegradable polymers [81, 82].

In spite iron magnetic particle generally be well tolerated by the organism, they can be used in the generation of reactive oxygen species, which cause direct damage to DNA, proteins or lipid molecules 

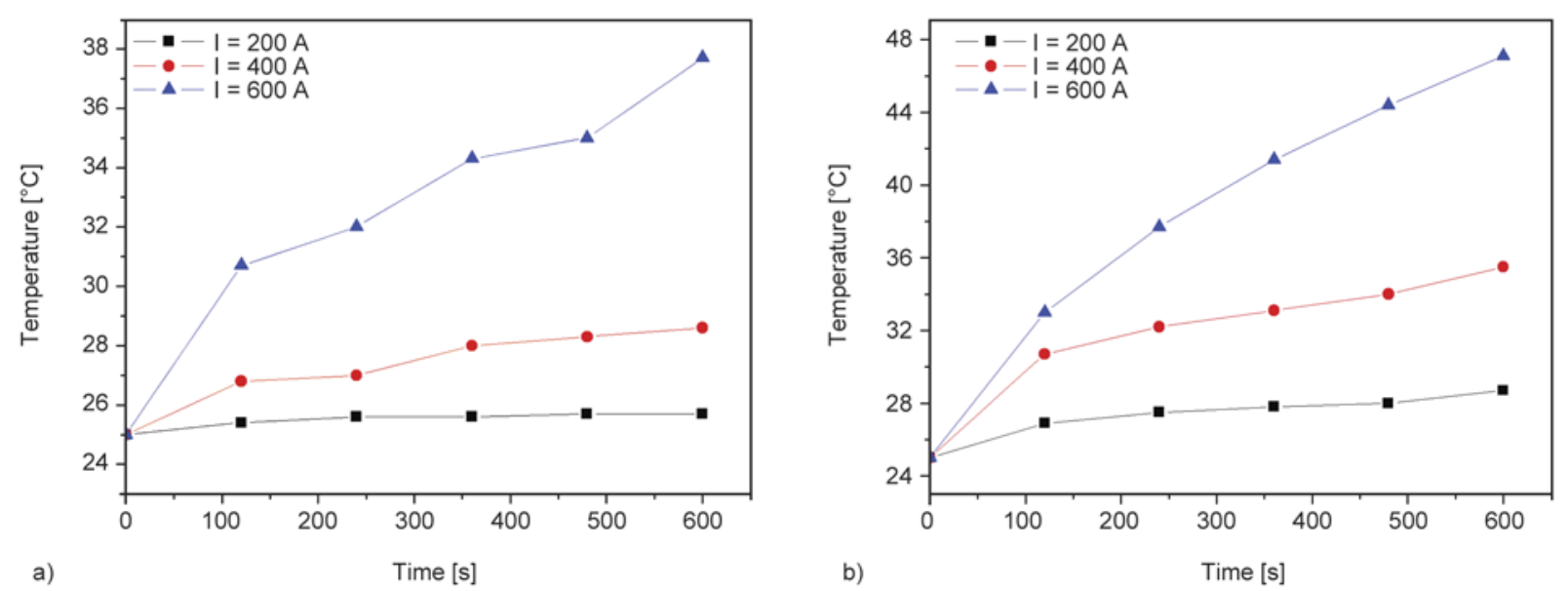

Figure 15. Heating curves of the magnetic microspheres of PLA/PEG/magnetite tested at two different concentration equal to $10 \mathrm{mg} / \mathrm{mL}$ (a) and $20 \mathrm{mg} / \mathrm{mL}$ (b)

[26]. Thus, magnetic particles are usually surfacemodified or coated with biocompatible and biodegradable polymer molecules such as PLA and PEG. In these work the UMC was well characterized by thermogravimetric and spectroscopic techniques, confirming the chemical linkage of PEG and PLA to the magnetite. This result is very encouraging since presented UMC could be biocompatible due to the use of the PLA and PEG, which are widely used in DDS $[83,84]$.

On the other hand this material could be useful to treat cancers, either alone or in combination with radiotherapy or chemotherapy. Therefore, the presented set of results allow us to infer that presented material, as well as constituting a new application of UFCC, could be very useful for the preparation of biomasked magnetic drug delivery systems.

\section{Conclusions}

Ugi four component condensation made the PEGylation of PLA and magnetite in a one pot step reaction possible. The results obtained indicate that one application of Ugi reaction is suitable for the PEGylation of magnetic particles. Superficial modification is the most important aspect of particles in biomedical applications to consider in order to improve their biocompatibility with biological entities. As a consequence, superficial modification of magnetite by Ugi reaction was corroborated by FTIR, DSC, TGA, optical and electronic microscopy, which made it possible to identify the copolymer (PLA-PEG) distributed around the magnetic particles. Besides, the synthesized material presented a good magnetic force, which was able to keep the magnetic composite in a specific location in the presence of any exter- nal magnetic field. In addition, the synthesized magnetic composite was able to form magnetic microspheres that could potentially be useful for the sitespecific delivery of any cytotoxic agent for cancer therapy. Also, these magnetic microspheres are useful to magnetic hyperthermia applications, improving the cancer treatment and even the welfare of the patients.

\section{Acknowledgements}

The authors thank Conselho Nacional de Desenvolvimento Científico e Tecnológico (CNPq-474940/2012-8 and 550030/ 2013-1), Coordenação de Aperfeiçoamento de Pessoal de Nível Superior (CAPES and CAPES-MES Cuba \# 154/12), Financiadora de Estudos e Projetos (FINEP PRESAL Ref. 1889/10), Rafael Moraes of LaBios laboratory by the induction magnetic test, LABEST laboratory and Fundação Carlos Chagas Filho de Amparo à Pesquisa do Estado do Rio de Janeiro (FAPERJ) for the financial support and scholarships.

\section{References}

[1] Zhou Y., Li H., Yang Y-W.: Controlled drug delivery systems based on calixarenes. Chinese Chemical Letters, 26, 825-828 (2015).

DOI: $10.1016 /$ j.cclet.2015.01.038

[2] Keith D., Cui H.: Fabrication of drug delivery systems using self-assembled peptide nanostructures. in 'Micro and nanofabrication using self-assembled biological nanostructures' (eds.: Castillo-León J., Svendsen W.) William Andrew, Oxford, 91-115 (2015).

DOI: 10.1016/B978-0-323-29642-7.00005-9

[3] Yoshida T.: Stimuli-sensitive polymers for drug delivery and diagnostic systems interacting with biosurfaces. in 'Switchable and responsive surfaces and materials for biomedical applications' (ed.: Zhang J.) Woodhead, Oxford, 235-258 (2015). 
[4] Yasin M. N., Svirskis D., Seyfoddin A., Rupenthal I. D.: Implants for drug delivery to the posterior segment of the eye: A focus on stimuli-responsive and tunable release systems. Journal of Controlled Release, 196, 208-221 (2014).

DOI: $10.1016 /$ j.jconrel.2014.09.030

[5] Elgadir M. A., Uddin M. S., Ferdosh S., Adam A., Chowdhury A. J. K., Sarker M. Z. I.: Impact of chitosan composites and chitosan nanoparticle composites on various drug delivery systems: A review. Journal of Food and Drug Analysis, in press (2015).

DOI: $10.1016 /$ j.jfda.2014.10.008

[6] Khanday M. A., Rafiq A.: Variational finite element method to study the absorption rate of drug at various compartments through transdermal drug delivery system. Alexandria Journal of Medicine, 51, 219-223 (2015).

DOI: $10.1016 /$ j.ajme.2014.09.001

[7] Moulton S. E., Wallace G. G.: 3-dimensional (3D) fabricated polymer based drug delivery systems. Journal of Controlled Release, 193, 27-34 (2014).

DOI: $10.1016 /$ j.jconrel.2014.07.005

[8] Rodrigues L. R.: Microbial surfactants: Fundamentals and applicability in the formulation of nano-sized drug delivery vectors. Journal of Colloid and Interface Science, 449, 304-316 (2015).

DOI: $10.1016 /$ j.jcis.2015.01.022

[9] Reddy K. R.: Controlled-release, pegylation, liposomal formulations: New mechanisms in the delivery of injectable drugs. The Annals of Pharmacotherapy, 34, 915-923 (2000).

DOI: $10.1345 / a p h .10054$

[10] Chen C-C., Chueh J-Y., Tseng H., Huang H-M., Lee SY.: Preparation and characterization of biodegradable PLA polymeric blends. Biomaterials, 24, 1167-1173 (2003).

DOI: $10.1016 / \mathrm{S} 0142-9612(02) 00466-0$

[11] Perry J. L., Reuter K. G., Kai M. P., Herlihy K. P., Jones S. W., Luft J. C., Napier M., Bear J. E., DeSimone J. M.: PEGylated PRINT nanoparticles: The impact of PEG density on protein binding, macrophage association, biodistribution, and pharmacokinetics. Nano Letters, 12, 5304-5310 (2012).

DOI: $10.1021 / \mathrm{nl} 302638 \mathrm{~g}$

[12] Huang M., Wu W., Qian J., Wan D-J., Wei X-L., Zhu JH.: Body distribution and in situ evading of phagocytic uptake by macrophages of long-circulating poly (ethylene glycol) cyanoacrylate-co- $n$-hexadecyl cyanoacrylate nanoparticles. Acta Pharmacologica Sinica, 26, 1512-1518 (2005).

DOI: $10.1111 / j .1745-7254.2005 .00216 . x$

[13] Fontana G., Licciardi M., Mansueto S., Schillaci D., Giammona G.: Amoxicillin-loaded polyethylcyanoacrylate nanoparticles: Influence of PEG coating on the particle size, drug release rate and phagocytic uptake. Biomaterials, 22, 2857-2865 (2001). DOI: $10.1016 /$ S0142-9612(01)00030-8
[14] Ohguchi Y., Kawano K., Hattori Y., Maitani Y.: Selective delivery of folate-PEG-linked, nanoemulsionloaded aclacinomycin A to KB nasopharyngeal cells and xenograft: Effect of chain length and amount of folatePEG linker. Journal of Drug Targeting, 16, 660-667 (2008).

DOI: 10.1080/10611860802201464

[15] Wang B., Zhang Y., Guo Z., Cheng J., Fang Z.: Biodegradable aliphatic/aromatic copoly(ester-ether)s: The effect of poly(ethylene glycol) on physical properties and degradation behavior. Journal of Polymer Research, 18, 187-196 (2011).

DOI: $10.1007 / \mathrm{s} 10965-010-9406-4$

[16] Zhong T., Deng C., Gao Y., Chen M., Zuo B.: Studies of in situ-forming hydrogels by blending PLA-PEG-PLA copolymer with silk fibroin solution. Journal of Biomedical Materials Research Part A, 100, 1983-1989 (2012).

DOI: $10.1002 / \mathrm{jbm} \cdot \mathrm{a} .33307$

[17] Tawfeek H. M., Evans A. R., Iftikhar A., Mohammed A. R., Shabir A., Somavarapu S., Hutcheon G. A., Saleem I. Y.: Dry powder inhalation of macromolecules using novel PEG-co-polyester microparticle carriers. International Journal of Pharmaceutics, 441, 611-619 (2013). DOI: 10.1016/j.ijpharm.2012.10.036

[18] Krawczak P.: Medical plastics: Serving healthcare. Express Polymer Letters, 7, 651 (2013). DOI: $10.3144 /$ expresspolymlett.2013.61

[19] Nkabinde L. A., Shoba-Zikhali L. N. N., SemeteMakokotlela B., Kalombo L., Swai H., Grobler A., Hamman J. H.: Poly (D,L-lactide-co-glycolide) nanoparticles: Uptake by epithelial cells and cytotoxicity. Express Polymer Letters, 8, 197-206 (2013). DOI: $10.3144 /$ expresspolymlett.2014.23

[20] Ke Y., Liu G. S., Wang J. H., Xue W., Du C., Wu G.: Preparation of carboxymethyl cellulose based microgels for cell encapsulation. Express Polymer Letters, 8, 841849 (2014). DOI: 10.3144 /expresspolymlett.2014.85

[21] Hamad K., Kaseem M., Yang H. W., Deri F., Ko Y. G.: Properties and medical applications of polylactic acid: A review. Express Polymer Letters, 9, 435-455 (2015). DOI: 10.3144/expresspolymlett.2015.42

[22] Mahmoudi M., Sant S., Wang B., Laurent S., Sen T.: Superparamagnetic iron oxide nanoparticles (SPIONs): Development, surface modification and applications in chemotherapy. Advanced Drug Delivery Reviews, 63, 24-46 (2011).

DOI: $10.1016 /$ j.addr.2010.05.006

[23] Laurent S., Dutz S., Häfeli U. O., Mahmoudi M.: Magnetic fluid hyperthermia: Focus on superparamagnetic iron oxide nanoparticles. Advances in Colloid and Interface Science, 166, 8-23 (2011). DOI: $\underline{10.1016 / \text { j.cis.2011.04.003 }}$ 
[24] Pollert E., Veverka P., Veverka M., Kaman O., Závěta K., Vasseur S., Epherred R., Gogliod G., Duguetd E.: Search of new core materials for magnetic fluid hyperthermia: Preliminary chemical and physical issues. Progress in Solid State Chemistry, 37, 1-14 (2009). DOI: 10.1016/j.progsolidstchem.2009.02.001

[25] Erathodiyil N., Ying J. Y.: Functionalization of inorganic nanoparticles for bioimaging applications. Accounts of Chemical Research, 44, 925-935 (2011).

DOI: $10.1021 / \operatorname{ar} 2000327$

[26] Frounchi M., Shamshiri S.: Magnetic nanoparticlesloaded PLA/PEG microspheres as drug carriers. Journal of Biomedical Materials Research Part A, 103, 18931898 (2015).

DOI: $10.1002 / \mathrm{jbm} . \mathrm{a} .35317$

[27] Pereira E. D., Souza F. G., Pinto J. C. C. S., Cerruti R., Santana C.: Synthesis, characterization and drug delivery profile of magnetic PLGA-PEG-PLGA/maghemite nanocomposite. Macromolecular Symposia, 343, 18-25 (2014).

DOI: $10.1002 /$ masy.201300168

[28] Sun Y., Zheng Y., Ran H., Zhou Y., Shen H., Chen Y., Chen H., Krupka T. M., Li A., Li P., Wang Z., Wang Z.: Superparamagnetic PLGA-iron oxide microcapsules for dual-modality US/MR imaging and high intensity focused US breast cancer ablation. Biomaterials, 33, 5854-5864 (2012).

DOI: 10.1016/j.biomaterials.2012.04.062

[29] Yu D., Zhang Y., Zhou X., Mao Z., Gao C.: Influence of surface coating of PLGA particles on the internalization and functions of human endothelial cells. Biomacromolecules, 13, 3272-3282 (2012).

DOI: $10.1021 / \mathrm{bm} 3010484$

[30] Ren J., Hong H., Ren T., Teng X.: Preparation and characterization of magnetic PLA-PEG composite nanoparticles for drug targeting. Reactive and Functional Polymers, 66, 944-951 (2006).

DOI: $10.1016 /$ j.reactfunctpolym.2006.01.002

[31] Ziegler T., Gerling S., Lang M.: Preparation of bioconjugates through an Ugi reaction. Angewandte Chemie International Edition, 39, 2109-2112 (2000).

DOI: 10.1002/1521-3773(20000616)39:12<2109::AIDANIE2109>3.0.CO;2-9

[32] de Nooy A. E. J., Masci G., Crescenzi V.: Versatile synthesis of polysaccharide hydrogels using the passerini and ugi multicomponent condensations. Macromolecules, 32, 1318-1320 (1999).

DOI: $10.1021 / \mathrm{ma9} 815455$

[33] Crescenzi V., Francescangeli A., Capitani D., Mannina L., Renier D., Bellini D.: Hyaluronan networking via Ugi's condensation using lysine as cross-linker diamine. Carbohydrate Polymers, 53, 311-316 (2003). DOI: $10.1016 / \mathrm{S} 0144-8617(03) 00079-1$
[34] Yang B., Zhao Y., Ren X., Zhang X., Fu C., Zhang Y., Wei Y., Tao L.: The power of one-pot: A hexa-component system containing $\pi-\pi$ stacking, Ugi reaction and RAFT polymerization for simple polymer conjugation on carbon nanotubes. Polymer Chemistry, 6, 509-513 (2014).

DOI: 10.1039/C4PY01323A

[35] Yang B., Zhao Y., Wang S., Zhang Y., Fu C., Wei Y., Tao L.: Synthesis of multifunctional polymers through the Ugi reaction for protein conjugation. Macromolecules, 47, 5607-5612 (2014).

DOI: $10.1021 / \mathrm{ma} 501385 \mathrm{~m}$

[36] Sehlinger A., Verbraeken B., Meier M. A. R., Hoogenboom R.: Versatile side chain modification via isocyanide-based multicomponent reactions: Tuning the LCST of poly(2-oxazoline)s. Polymer Chemistry, 6, 3828-3836 (2015).

DOI: 10.1039/C5PY00392J

[37] Dömling A., Ugi I.: Multicomponent reactions with isocyanides. Angewandte Chemie International Edition, 39, 3168-3210 (2000).

DOI: 10.1002/1521-3773(20000915)39:18<3168::AIDANIE3168>3.0.CO;2-U

[38] RuizMoreno R. G., Martinez A. I., Castro-Rodriguez R., Bartolo P.: Synthesis and characterization of citrate coated magnetite nanoparticles. Journal of Superconductivity and Novel Magnetism, 26, 709-712 (2013). DOI: $10.1007 / \mathrm{s} 10948-012-1790-\mathrm{Z}$

[39] Lucke A., Fustella E., Teßmar J., Gazzaniga A., Göpferich A.: The effect of poly(ethylene glycol)-poly(D,Llactic acid) diblock copolymers on peptide acylation. Journal of Controlled Release, 80, 157-168 (2002). DOI: 10.1016/S0168-3659(02)00020-2

[40] Souza F. G., Ferreira A. C., Varela A., Oliveira G. E., Machado F., Pereira E. D., Fernandes E., Pinto J. C., Nele M.: Methodology for determination of magnetic force of polymeric nanocomposites. Polymer Testing, 32, 1466-1471 (2013). DOI: $10.1016 /$ j.polymertesting.2013.09.018

[41] Ribeiro G. A. P.: Magnetic properties of the matter: A first contact (in Portuguese). Revista Brasileira de Ensino de Física, 22, 299-305 (2000).

[42] Lu A-H., Salabas E. L., Schüth F.: Magnetic nanoparticles: Synthesis, protection, functionalization, and application. Angewandte Chemie International Edition, 48, 1222-1244 (2007).

DOI: 10.1002 /anie. 200602866

[43] Martins T. S., Isolani P. C.: Rare earths: Industrial and biological applications (in Portugese). Química Nova, 28, 111-117 (2005). DOI: $10.1590 / \mathrm{S} 0100-40422005000100020$

[44] Rajagopalan S., Gonias S. L., Pizzo S. V.: A nonantigenic covalent streptokinase-polyethylene glycol complex with plasminogen activator function. The Journal of Clinical Investigation, 75, 413-419 (1985).

DOI: $10.1172 /$ JCI111715 
[45] Beauchamp C. O., Gonias S. L., Menapace D. P., Pizzo S. V.: A new procedure for the synthesis of polyethylene glycol-protein adducts; Effects on function, receptor recognition, and clearance of superoxide dismutase, lactoferrin, and $\alpha_{2}$-macroglobulin. Analytical Biochemistry, 131, 25-33 (1983).

DOI: 10.1016/0003-2697(83)90131-8

[46] Lukyanov A. N., Sawant R. M., Hartner W. C., Torchilin V. P.: PEGylated dextran as long-circulating pharmaceutical carrier. Journal of Biomaterials Science, Polymer Edition, 15, 621-630 (2004). DOI: $10.1163 / 156856204323046889$

[47] Zhang J., Fan X., Liu Y., Bo L., Liu X.: Synthesis of poly(ethylene glycol)-metaxalone conjugates and study of its controlled release in vitro. International Journal of Pharmaceutics, 332, 125-131 (2007). DOI: $10.1016 /$ j.ijpharm.2006.09.039

[48] Bischo R.: Polyethylene-hirudinea conjugates, preparation and use in thrombosis treatment (in Spanish). Spanish Patent 2169 037, Spain (1993).

[49] Wang X-L., Mou Y-R., Chen S-C., Shi J., Wang Y-Z.: A water-soluble PPDO/PEG alternating multiblock copolymer: Synthesis, characterization, and its gel-sol transition behavior. European Polymer Journal, 45, 1190-1197 (2009).

DOI: 10.1016/j.eurpolymj.2008.12.038

[50] Narayan R., Bandyopadhyay A., Bose S.: Biomaterials science: Processing, properties, and applications. Wiley, Westerville (2011).

[51] Liu Q., Yang X., Xu H., Pan K., Yang Y.: Novel nanomicelles originating from hydroxyethyl starch- $g$-polylactide and their release behavior of docetaxel modulated by the PLA chain length. European Polymer Journal, 49, 3522-3529 (2013). DOI: $10.1016 /$ j.eurpolymj.2013.08.012

[52] Sin L. T., Rahmat A. R., Rahman W. A. W. A. Polylactic acid: PLA biopolymer technology and applications. William Andrew, Chicago (2012).

[53] Mercado-Pagán Á. E., Kang Y., Ker D. F. E., Park S., Yao J., Bishop J., Yang Y.: Synthesis and characterization of novel elastomeric poly(D,L-lactide urethane) maleate composites for bone tissue engineering. European Polymer Journal, 49, 3337-3349 (2013).

DOI: 10.1016/j.eurpolymj.2013.07.004

[54] Selukar B. S., Parwe S. P., Mohite K. K., Garnaik B.: Synthesis and characterization of linear polylactic acid-based urethanes using tin modified solid cloisite30B catalyst. Advanced Materials Letters, 3, 161-171 (2012). DOI: 10.5185/amlett.2011.11325

[55] Achmad F., Yamane K., Quan S., Kokugan T.: Synthesis of polylactic acid by direct polycondensation under vacuum without catalysts, solvents and initiators. Chemical Engineering Journal, 151, 342-350 (2009). DOI: $10.1016 /$ j.cej.2009.04.014
[56] Xiao L., Wang B., Yang G., Gauthier M.: Poly(lactic acid)-based biomaterials: Synthesis, modification and applications. in 'Biomedical science, engineering and technology' (ed.: Ghista D. N.), Rijeka, 247-282 (2012). DOI: $10.5772 / 23927$

[57] Zhou S., Deng X., Li X., Jia W., Liu L.: Synthesis and characterization of biodegradable low molecular weight aliphatic polyesters and their use in protein-delivery systems. Journal of Applied Polymer Science, 91, 18481856 (2004). DOI: $10.1002 / a p p .13385$

[58] Chia H-H., Yang Y-Y., Chung T-S., Ng S., Heller J.: Auto-catalyzed poly(ortho ester) microspheres: A study of their erosion and drug release mechanism. Journal of Controlled Release, 75, 11-25 (2001). DOI: $10.1016 / \mathrm{S} 0168-3659(01) 00362-5$

[59] Cavalcante L. C. D., Lage M. C. S. M., Fabris J. D.: Chemical analysis of red pigment in human bone (in Portugese). Química Nova, 31, 1117-1120 (2008). DOI: $10.1590 / \mathrm{S} 0100-40422008000500034$

[60] Andrade A. L., Souza D. M., Pereira M. C., Fabris J. D., Domingues R. Z.: Synthesis and characterization of magnetic nanoparticles coated with silica through a sol-gel approach. Cerâmica, 55, 420-424 (2009). DOI: $10.1590 / \mathrm{S} 0366-69132009000400013$

[61] Lehnhoff S., Goebel M., Karl R. M., Klösel R., Ugi I.: Stereoselective syntheses of peptide derivatives with 2 -acetamido-3,4,6-tri- $O$-acetyl-1-amino-2-deoxy- $\beta$-Dglucopyranose by four-component condensation. Angewandte Chemie International Edition in English, 34, 1104-1107 (1995).

DOI: $10.1002 /$ anie. 199511041

[62] Dömling A.: Recent developments in isocyanide based multicomponent reactions in applied chemistry. Chemical Reviews, 106, 17-89 (2006).

DOI: $10.1021 / \mathrm{cr} 0505728$

[63] Paul M-A., Alexandre M., Degée P., Henrist C., Rulmont A., Dubois P.: New nanocomposite materials based on plasticized poly(L-lactide) and organo-modified montmorillonites: Thermal and morphological study. Polymer, 44, 443-450 (2003).

DOI: $10.1016 / \mathrm{S} 0032-3861(02) 00778-4$

[64] Ozkoc G., Kemaloglu S.: Morphology, biodegradability, mechanical, and thermal properties of nanocomposite films based on PLA and plasticized PLA. Journal of Applied Polymer Science, 114, 2481--2487 (2009). DOI: 10.1002/app.30772

[65] Yang J., Zhao T., Liu L., Zhou Y., Li G., Zhou E., Chen $\mathrm{X}$.: Isothermal crystallization behavior of the poly(Llactide) block in poly(L-lactide)-poly(ethylene glycol) diblock copolymers: Influence of the PEG block as a diluted solvent. Polymer Journal, 38, 1251-1257 (2006). DOI: 10.1295/polymj.PJ2006094

[66] Thomas S., Durand D., Chassenieux C., Jyotishkumar P.: Handbook of biopolymer-based materials: From blends and composites to gels and complex networks. Wiley, Weinheim (2013). 
[67] Song Y-P., Wang D-Y., Wang X-L., Lin L., Wang Y-Z.: A method for simultaneously improving the flame retardancy and toughness of PLA. Polymers for Advanced Technologies, 22, 2295-2301 (2011).

DOI: $10.1002 /$ pat. 1760

[68] Feuser P. E., dos Santos Bubniak L., dos Santos Silva M. C., da Cas Viegas A., Fernandes A. C., Ricci-Junior E., Nele M., Tedesco A. C., Sayer C., de Araújo P. H. H.: Encapsulation of magnetic nanoparticles in poly(methyl methacrylate) by miniemulsion and evaluation of hyperthermia in U87MG cells. European Polymer Journal, 68, 355-365 (2015).

DOI: $10.1016 /$ j.eurpolymj.2015.04.029

[69] Pereira E. D., Souza F. G., Santana C. I., Soares D. Q., Lemos A. S., Menezes L. R.: Influence of magnetic field on the dissolution profile of cotrimoxazole inserted into poly(lactic acid-co-glycolic acid) and maghemite nanocomposites. Polymer Engineering and Science, 53, 2308-2317 (2013).

DOI: $10.1002 /$ pen.23606

[70] Xu X. X., Zheng Y. F.: Synthesis and characterization of magnetic nanoparticles and their reinforcement in polyurethane film. Key Engineering Materials, 324325, 659-662 (2006).

DOI: 10.4028/www.scientific.net/KEM.324-325.659

[71] Neves J. S., de Souza F. G., Suarez P. A. Z., Umpierre A. P., Machado F.: In situ production of polystyrene magnetic nanocomposites through a batch suspension polymerization process. Macromolecular Materials and Engineering, 296, 1107-1118 (2011).

DOI: $10.1002 /$ mame. 201100050

[72] de Souza K. C., Mohallem N. D. S., de Sousa E. M. B.: Magnetic nanocomposites: Potential for applications in biomedicine (in Portugese). Química Nova, 34, 16921703 (2011).

DOI: $10.1590 / \mathrm{S} 0100-40422011001000003$

[73] Jeong U., Teng X., Wang Y., Xia Y.: Superparamagnetic colloids: Controlled synthesis and niche applications. Advanced Materials, 19, 33-60 (2006). DOI: 10.1002/adma.200600674

[74] de Souza F., Marins J. A., Pinto J., de Oliveira G., Rodrigues C., Lima L.: Magnetic field sensor based on a maghemite/polyaniline hybrid material. Journal of Materials Science, 45, 5012-5021 (2010).

DOI: $10.1007 / \mathrm{s} 10853-010-4321-\mathrm{y}$

[75] Grance E. G. O., Souza F. G., Varela A., Pereira E. D., Oliveira G. E., Rodrigues C. H. M.: New petroleum absorbers based on lignin-CNSL-formol magnetic nanocomposites. Journal of Applied Polymer Science, 126, E304-E311 (2012).

DOI: $10.1002 /$ app.36998
[76] Schimanke G., Martin M.: In situ XRD study of the phase transition of nanocrystalline maghemite $(\gamma$ $\left.\mathrm{Fe}_{2} \mathrm{O}_{3}\right)$ to hematite $\left(\alpha-\mathrm{Fe}_{2} \mathrm{O}_{3}\right)$. Solid State Ionics, 136137, 1235-1240 (2000). DOI: $10.1016 / \mathrm{S} 0167-2738(00) 00593-2$

[77] Hui C., Shen C., Tian J., Bao L., Ding H., Li C., Tian Y., Shi X., Gao H-J.: Core-shell $\mathrm{Fe}_{3} \mathrm{O}_{4} @ \mathrm{SiO}_{2}$ nanoparticles synthesized with well-dispersed hydrophilic $\mathrm{Fe}_{3} \mathrm{O}_{4}$ seeds. Nanoscale, 3, 701-705 (2011).

DOI: $10.1039 /$ C0NR00497A

[78] Sarkar A., Biswas S. K., Pramanik P.: Design of a new nanostructure comprising mesoporous $\mathrm{ZrO}_{2}$ shell and magnetite core $\left(\mathrm{Fe}_{3} \mathrm{O}_{4} @ \mathrm{mZrO}_{2}\right)$ and study of its phosphate ion separation efficiency. Journal of Materials Chemistry, 10, 4417-4424 (2010).

DOI: $10.1039 / \mathrm{B} 925379 \mathrm{C}$

[79] Lochmann A., Nitzsche H., von Einem S., Schwarz E., Mäder K.: The influence of covalently linked and free polyethylene glycol on the structural and release properties of rhBMP-2 loaded microspheres. Journal of Controlled Release, 147, 92-100 (2010).

DOI: $10.1016 /$ j.jconrel.2010.06.021

[80] Essa S., Rabanel J. M., Hildgen P.: Effect of polyethylene glycol (PEG) chain organization on the physicochemical properties of poly(D, L-lactide) (PLA) based nanoparticles. European Journal of Pharmaceutics and Biopharmaceutics, 75, 96-106 (2010).

DOI: 10.1016/j.ejpb.2010.03.002

[81] Shah S. A., Majeed A., Rashid K., Awan S-U.: PEGcoated folic acid-modified superparamagnetic $\mathrm{MnFe}_{2} \mathrm{O}_{4}$ nanoparticles for hyperthermia therapy and drug delivery. Materials Chemistry and Physics, 138, 703-708 (2013).

DOI: $10.1016 /$ j.matchemphys.2012.12.044

[82] Qu J., Liu G., Wang Y., Hong R.: Preparation of $\mathrm{Fe}_{3} \mathrm{O}_{4-}$ chitosan nanoparticles used for hyperthermia. Advanced Powder Technology, 21, 461-467 (2010).

DOI: $10.1016 /$ j.apt.2010.01.008

[83] Scott G.: Degradable polymers: Principles and applications. Kluwer, Dordrecht (2002).

[84] Jorgensen L., Nielson H. M.: Delivery technologies for biopharmaceuticals: Peptides, proteins, nucleic acids and vaccines. Wiley, Chichester (2009).

[85] Sarasua J. R., Arraiza A. L., Balerdi P., Maiza I.: Crystallization and thermal behaviour of optically pure polylactides and their blends. Journal of Materials Science, 40, 1855-1862 (2005). DOI: $10.1007 / \mathrm{s} 10853-005-1204-8$ 